\title{
Training of adult psychiatrists and child and adolescent psychiatrists in europe: a systematic review of training characteristics and transition from child/adolescent to adult mental health services
}

\author{
For the Milestone Consortium, Frederick Russet ${ }^{1{ }^{*+}}$ (D), Veronique Humbertclaude ${ }^{1 \dagger}$, Gwen Dieleman ${ }^{2}$, \\ Katarina Dodig-Ćurković ${ }^{3}$, Gaelle Hendrickx ${ }^{4}$, Vlatka Kovač ${ }^{3}$, Fiona McNicholas ${ }^{5}$, Athanasios Maras 6,7, \\ Santosh Paramala ${ }^{8,9,10}$, Moli Paul ${ }^{11,12}$, Ulrike M. E. Schulze ${ }^{13}$, Giulia Signorini ${ }^{14}$, Cathy Street ${ }^{11}$, Priya Tah ${ }^{11}$, \\ Helena Tuomainen ${ }^{11}$, Swaran P. Singh ${ }^{11}$, Sabine Tremmery ${ }^{4,15+}$ and Diane Purper-Ouakil ${ }^{1+}$
}

\begin{abstract}
Background: Profound clinical, conceptual and ideological differences between child and adult mental health service models contribute to transition-related discontinuity of care. Many of these may be related to psychiatry training.

Methods: A systematic review on General Adult Psychiatry (GAP) and Child and Adult Psychiatry (CAP) training in Europe, with a particular focus on transition as a theme in GAP and CAP training.

Results: Thirty-four full-papers, six abstracts and seven additional full text documents were identified. Important variations between countries were found across several domains including assessment of trainees, clinical and educational supervision, psychotherapy training and continuing medical education. Three models of training were identified: i) a generalist common training programme; ii) totally separate training programmes; iii) mixed types. Only two national training programs (UK and Ireland) were identified to have addressed transition as a topic, both involving CAP exclusively.
\end{abstract}

Conclusion: Three models of training in GAP and CAP across Europe are identified, suggesting that the harmonization is not yet realised and a possible barrier to improving transitional care. Training in transition has only recently been considered. It is timely, topical and important to develop evidence-based training approaches on transitional care across Europe into both CAP and GAP training.

\section{Background}

Young people with psychological, emotional or behavioural problems who fall through the care gap when negotiating the transition boundary between child and adult mental health services are at risk of poorer mental

* Correspondence: f-russet@chu-montpellier.fr

Frederick Russet and Veronique Humbertclaude shared equally in this work as first authors.

Diane Purper-Ouakil and Sabine Tremmery are co-leaders for this paper. ${ }^{1} \mathrm{CHU}$ Montpellier-Saint Eloi, Médecine Psychologique de l'Enfant et de I'Adolescent, 80, Av Fliche, 34295 Montpellier Cedex 5, France

Full list of author information is available at the end of the article health outcomes [1]. They may develop more serious mental disorders than those who experience a smooth and purposeful transition [1]. Referred to as "mental health service transition", the move of young patients from child and adolescent mental health services (CAMHS) to adult mental health services (AMHS) is now understood to be more than an 'event' or a simple transfer [2]. It is a process, requiring therapeutic intent which prepares the adolescent for transition and includes a period of handover or joint care, transition-planning meetings and transfer of case notes or information summaries [3]. The

(c) The Author(s). 2019 Open Access This article is distributed under the terms of the Creative Commons Attribution 4.0 International License (http://creativecommons.org/licenses/by/4.0/), which permits unrestricted use, distribution, and reproduction in any medium, provided you give appropriate credit to the original author(s) and the source, provide a link to the Creative Commons license, and indicate if changes were made. The Creative Commons Public Domain Dedication waiver (http://creativecommons.org/publicdomain/zero/1.0/) applies to the data made available in this article, unless otherwise stated. 
importance of transitional care has been identified in young people with other chronic conditions such as congenital heart disease, juvenile arthritis, epilepsy and diabetes both at the individual and service provision levels [4-6].

Like the description of transition in physical medicine, transition in Mental Health Care (MHC) has multidimensional and multidisciplinary aspects [7-9]. The goal in transition is to maximize lifelong functioning and potential of young people through the provision of high-quality, developmentally appropriate health care that continues uninterrupted as the individual moves from adolescence to adulthood [8]. Appropriate transition is crucial for young service users and transition-related discontinuity of care is now considered as a major socioeconomic and societal challenge for the European Union (EU).

The EU-funded research program 'MILESTONE project' aims to improve transition of young patients from CAMHS to AMHS through a collaborative project involving eight different countries (www.milestone-transitionstudy.eu/) [10]. One of the MILESTONE work packages is specifically dedicated to training as a potential avenue for improvement. The rationale of this topic relies on previous findings having identified poor communication between CAHMS and AHMS, differences in care models and organization between CAHMS and AHMS, overload of services and absence of specific training as main obstacles to transition [11]. This has been confirmed by first findings from the MILESTONE consortium: Signorini and al. (2017) [12] identified lack of connection between CAMHS and AMHS, poor specific competencies and absence of systematic assessment and procedures for transitioning as targets for improvement. Implementation of specific evaluations and protocols will require specific training. Further training issues are the knowledge and skills required for planning transition, awareness of developmental needs, multidisciplinary collaboration and working with young people and families [1].

With the aim of developing and implementing training models and training procedures for clinicians across the $\mathrm{EU}$, this work package is responsible for exploring how transition processes and outcomes might be related to the training of professionals working in mental health services in Europe. To the best of our knowledge, no study or review has addressed the training of professionals working in mental health services with a specific focus on transition between CAMHS and AMHS. As a prerequisite for further studies about relationships between transition and training, we conducted a systematic review of the structure and content of General and Adult Psychiatry (GAP) and Child and Adolescent Psychiatry (CAP) training in Europe. The aims were: $1 /$ to describe the organization and structure of current training across Europe in GAP and CAP, as defined by the European Union of Medical Specialists (UEMS) [13]; and $2 /$ to assess if and how transition is addressed in any of the European GAP and CAP training programs.

\section{Methods}

The review was carried out following the standards of the Preferred Reporting Items for Systematic Reviews and Meta-Analyses (PRISMA) [14].

\section{Search strategy and data source}

Two investigators (FR, VH) searched the literature through the following databases: PsycInfo-Esbco (Psycinfo, Eric, PsycARTICLES, Psychology and Behavioral Sciences Collection), PubMed and the revue collection Science Direct (Fig. 1). The review regarded organization and structure of training of CAP and GAP in Europe and was performed using subject headings with the following algorithm: (Psychiatr* AND Training AND Europ*); and (Psychiatr* AND Training AND [Name of 39 European countries]). These two algorithms were used in the following search sections: in "abstract" for PsycInfo-Esbco; in "title and abstract" for PubMed; in "Title, abstract and keywords" for Science Direct. Only references published after January 2000 were considered because there was no point in considering older articles due to reforms regularly implemented in psychiatry training. The search was conducted in March 2018.

The same investigators searched for the grey literature using various online sources for each country (e.g. medical associations, scientific societies, and universities), focusing on national psychiatry training programs and expert papers. Additional information was searched for by scanning the reference lists of identified papers. Authors were contacted if the full-text paper was not available.

\section{Data selection and quality assessment}

The titles and abstracts of articles were screened for relevance by two reviewers (FR, AS). Potentially relevant articles were obtained in full and further screened to determine if they met the eligibility criteria detailed in Table 1. Authors were contacted when a full paper was not available. When a full paper was unavailable, the corresponding abstract was included if it provided relevant information about psychiatry training (Table 1). Expert papers, opinion papers and narrative reviews were included only if they met minimum standards according to JBI Critical Appraisal Checklist for Narrative, Expert Opinion and Text or JBI Critical Appraisal Checklist for Systematic Reviews and Research Syntheses [15] (Assessment Table available on request). For quantitative studies, the Hawker checklist [16] was used for critical appraisal. This checklist includes nine items. For every item, 


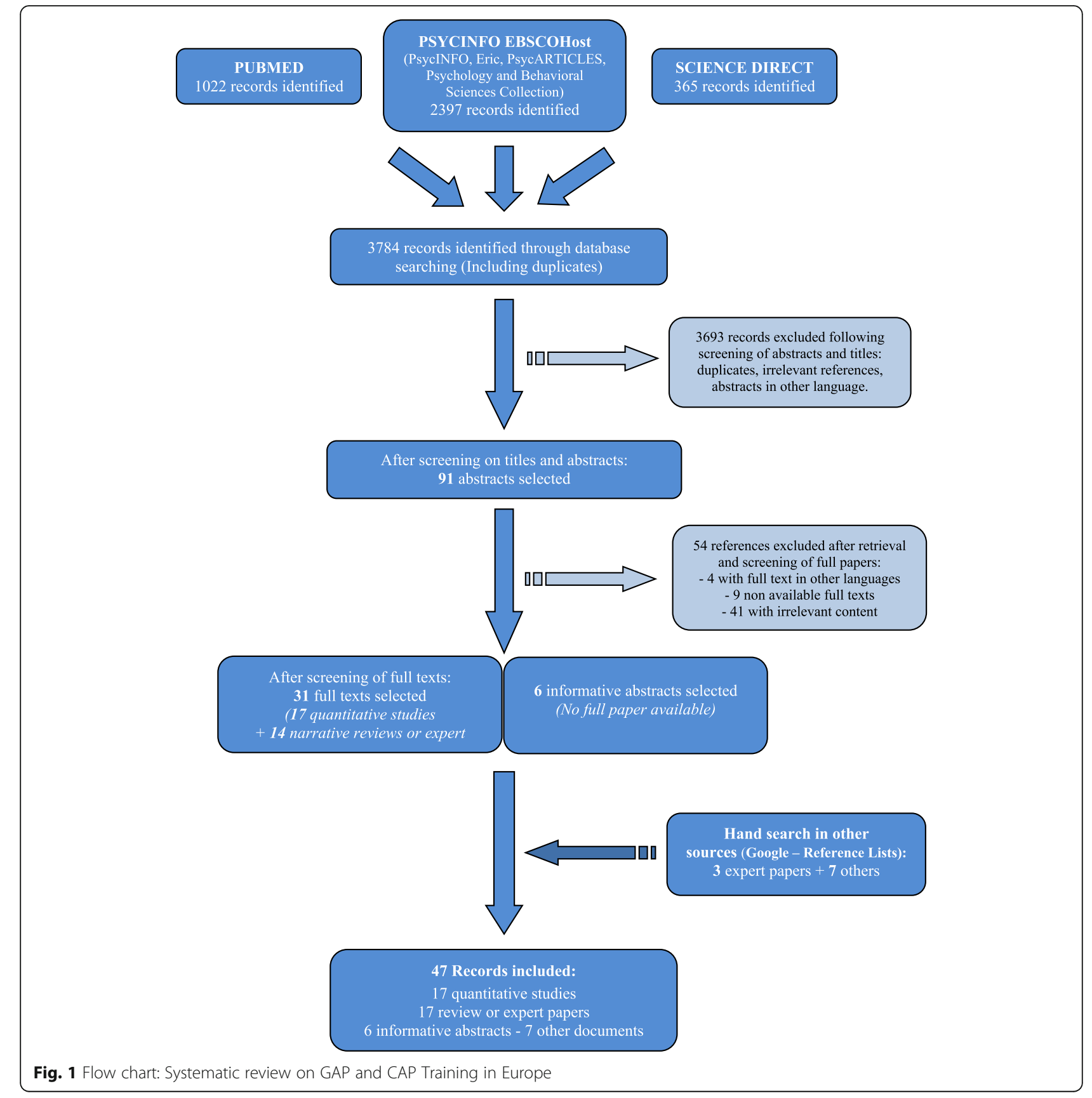

each study was given a quality score of 1 (very poor), 2 (poor), 3 (fair) or 4 (good), and finally granted a summed general score, with a maximum potential score of 36 . Reviewers made their screening and assessments independently. In case of discrepancy in the screening, a consensus was searched. In case of discrepancy in the assessment, research papers were appraised jointly to reach an agreement.

\section{Data extraction and analysis}

Two data extraction forms (Additional file 1: Tables S1 \& S2) were designed to collate information about GAP and CAP training for each European country according to the main aspects mentioned in the UEMS recommendations [13]: training program, structure and duration, quality control and assessment. Terms were defined according to the glossary established by UEMS [13] (Additional file 1: Appendix 1).

\section{Results}

Forty-seven references were identified following the search regarding GAP and CAP training in Europe (Fig. 1). The quality scores of the 17 quantitative studies 
Table 1 Eligibility criteria (Inclusion and exclusion criteria)

\begin{tabular}{ll}
\hline Population & Europe as a continent \\
& 39 European countries (Albania, Austria, Belgium, Bosnia, \\
& Bulgaria, Czech Republic, Cyprus, Croatia, Denmark, Estonia, \\
& Finland, France, Germany, Greece, Hungary, Ireland, Iceland, \\
& Italy, Latvia, Lithuania, Luxembourg, Malta, Moldavia, \\
& Montenegro, Netherlands, Norway, Poland, Portugal, \\
& Romania, Russia, Serbia, Slovakia, Slovenia, Spain, Sweden, \\
& Switzerland, Turkey, Ukraine, UK) \\
Interventions & Psychiatry: General adult psychiatry, child and adolescent \\
& psychiatry, psychiatry in general or other psychiatry \\
& specialities if GAP or CAP were mentioned. \\
& Training: all information related to specialist education \\
& after medical school (postgraduate training) \\
& Transition of patients from CAHMS to AHMS: identified as \\
& a process aiming to support young patients who move \\
& from CAHMS to AHMS - any kind of information \\
& concerning training to transition during specialist \\
& education. \\
Study designs & All types of studies: Reviews (systematic or narrative); \\
& Observational studies: surveys; Expert opinions; national \\
& programmes. \\
Eublications & English, French or Spanish peer-reviewed journals \\
& Published from 01/01/2000
\end{tabular}

ranged from 17 to 30 , out of a possible 36 (Table 2). The aims, methods and major aggregated data are described for full-text articles (Tables 3 and 4) and for abstracts (Table 5).

\section{General and adult psychiatry (GAP)}

Available data regarding GAP training in Europe (absolute values and percentages) are summarized in Table 6 (detailed for each country in Additional file 2: Table S3 and Additional file 3:Table S4). Mentioned percentages were calculated on the total number of countries for which data were available. An established national standardized program with a mean duration of 4 to 6 years was evident in $76 \%$ of 34 European countries (data missing for Cyprus, Iceland, Luxembourg, Moldavia, Montenegro, and Ukraine). The compulsory and common set of fundamental knowledge for GAP, as defined by the UEMS [13] was largely followed by all countries, especially in relation to addictions (97\% of countries), CAP (96\%) and forensic psychiatry (88\%), but less so in relation to old age psychiatry (69\%) and psychotherapy (66\%). In terms of common set of skills, placements in in-patient, outpatient and emergency psychiatry were compulsory in all countries, while training in liaison and consultation psychiatry was required in only $55 \%$ of countries. The evaluation of trainees varied considerably between countries, from a continuous examination during training by supervisor and workplace based-assessment (WPBA) to only a single final examination set by an examination board.

The following items address relevant issues regarding training, but information was available only for some countries or was aggregated in publications:

* Structured theoretical training was provided in 18/22 (82\%) countries [19], including Belgium, France, Germany, the Netherlands and Sweden [47], sometimes with variations within countries regarding implementation and content, for instance in France [57] or in Spain [25].

* Regarding Adult Psychiatry as a topic in the training program, the duration varied according to the training model used, with longer training in countries with separate specialities. Oakley \& Malik [23] reported a mean training time of 23 months in 5 countries with a common training path (e.g. Bosnia, Croatia, Czech Republic, Estonia and France) compared to a mean training time of 39 months in 16 countries with separate training for adult psychiatry (e.g. Germany, Italy, UK).

* Training in psychodynamic psychotherapy, Cognitive Behavioural Therapy (CBT), family therapy and systemic therapy were the most widely available therapy courses $[23,24]$. The implementation of training in psychotherapy has rarely been investigated. Lee and Noonan [56] conducted a survey among 62

Table 2 Summary of quality score of the 17 quantitative studies

\begin{tabular}{|c|c|c|c|c|c|}
\hline & Good (rated 4) & Fair (rated 3) & Poor (rated 2) & Very poor (rated 1) & Total rated \\
\hline Abstract and title & 9 & 4 & 0 & 4 & 17 \\
\hline Introduction and aims & 3 & 11 & 3 & 0 & 17 \\
\hline Method and data & 0 & 12 & 5 & 0 & 17 \\
\hline Sampling & 2 & 6 & 9 & 0 & 17 \\
\hline Data analysis & 3 & 2 & 1 & 11 & 17 \\
\hline Ethics and bias & 2 & 4 & 6 & 5 & 17 \\
\hline Findings/results & 12 & 6 & 0 & 0 & 17 \\
\hline Transferability/generalizability & 0 & 12 & 5 & 0 & 17 \\
\hline Implications and usefulness & 5 & 7 & 0 & 0 & 17 \\
\hline Distribution of Total score $(\max$ score $=36)$ & \multicolumn{5}{|c|}{$1 \times 17-2 \times 19-1 \times 20-1 \times 24-3 \times 25-1 \times 26-2 \times 27-1 \times 28-2 \times 29-3 \times 30$} \\
\hline
\end{tabular}




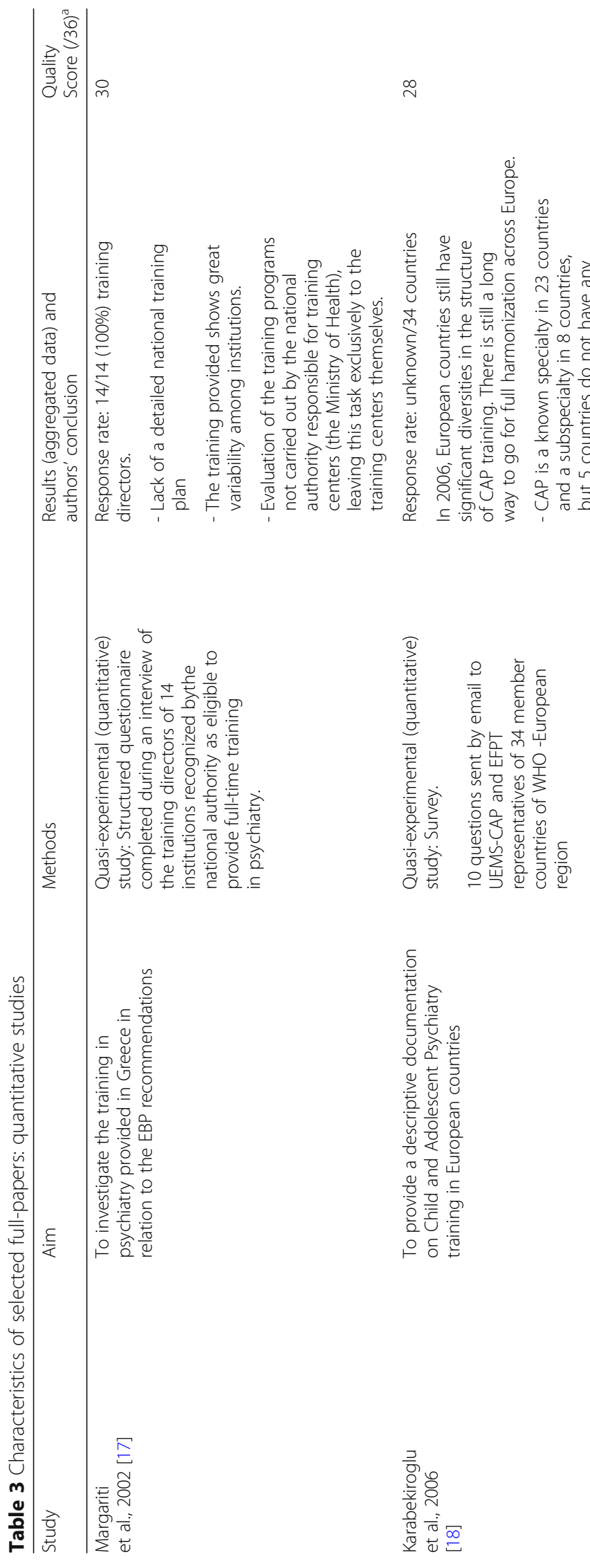




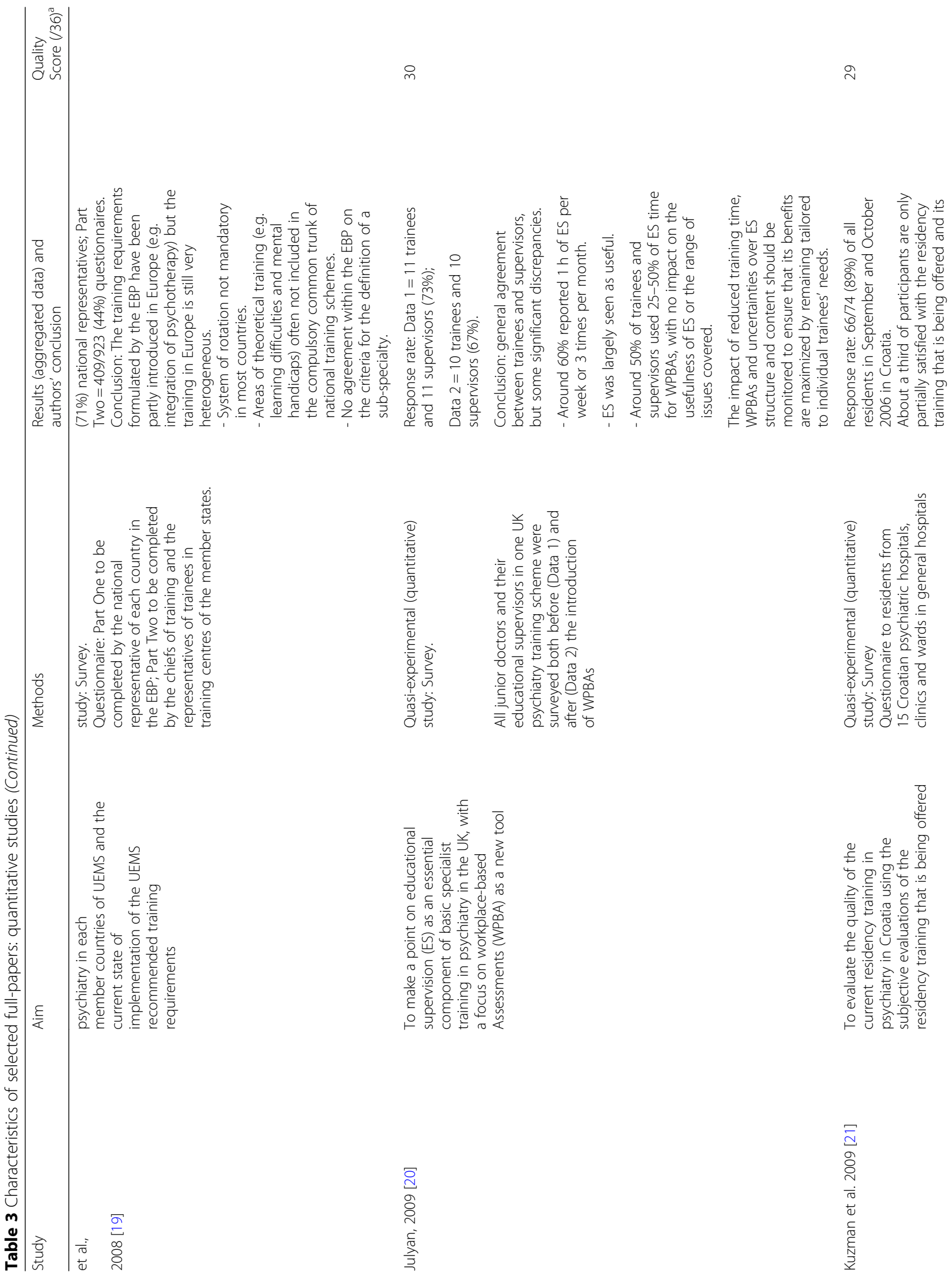




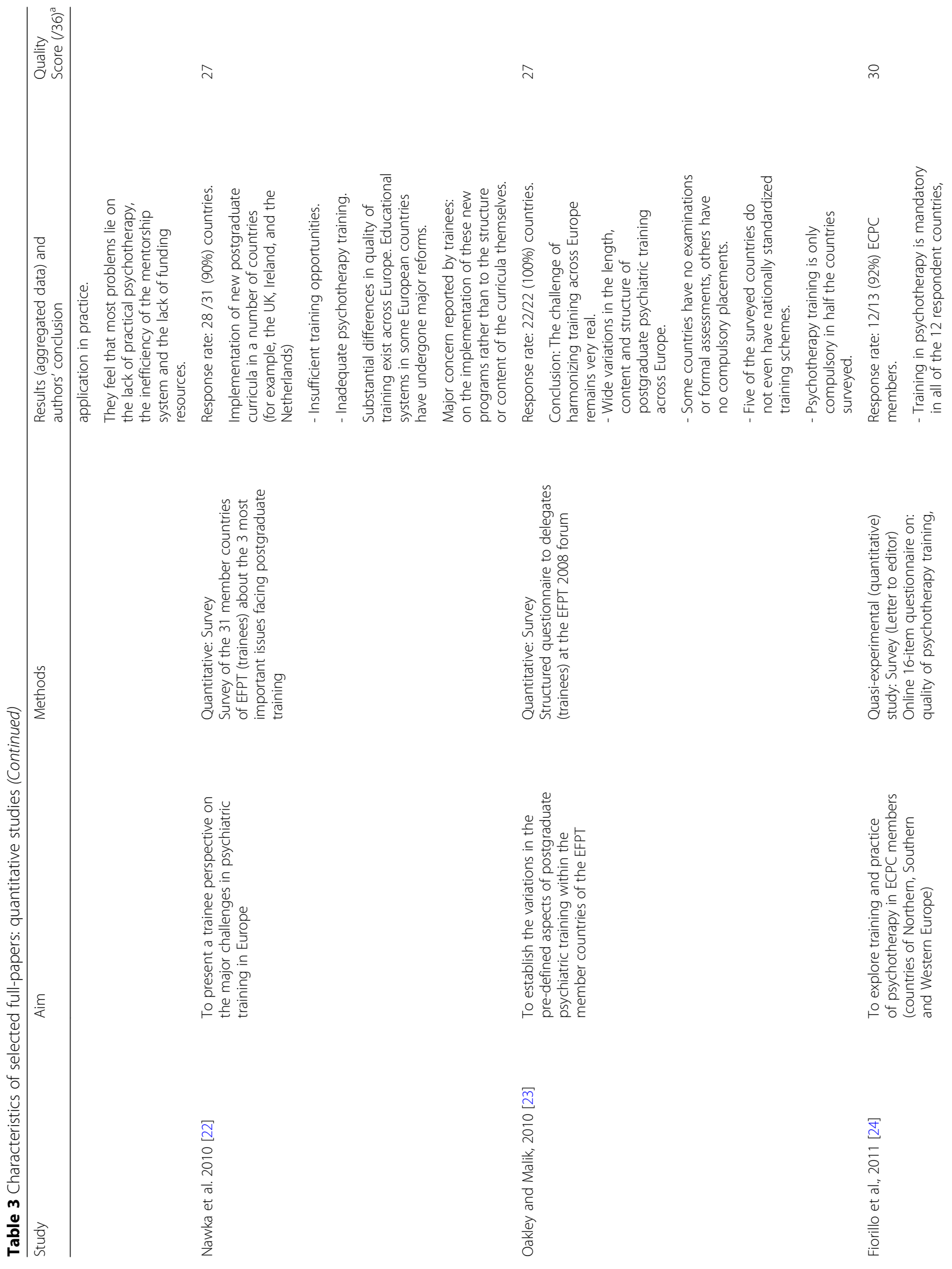




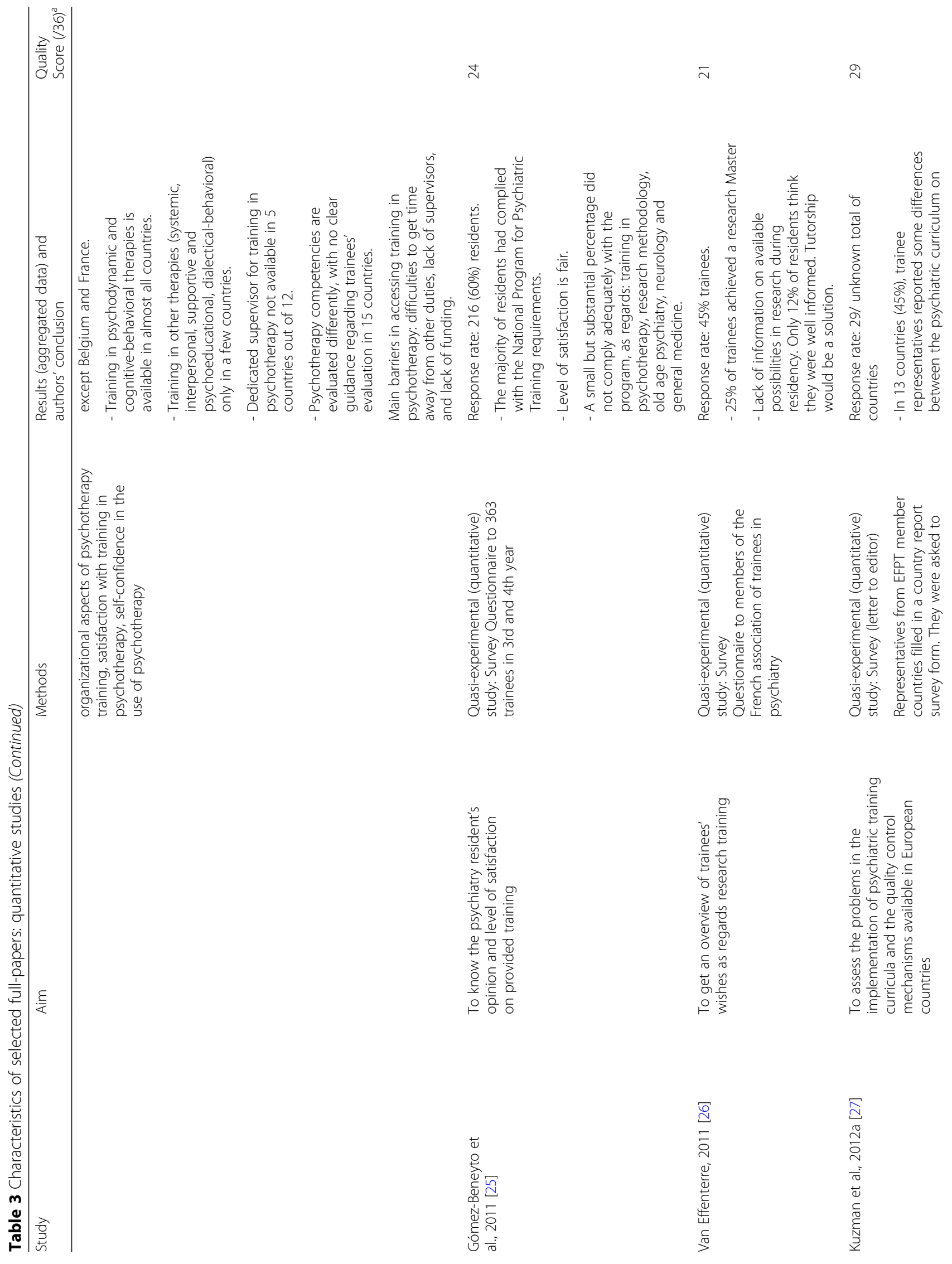




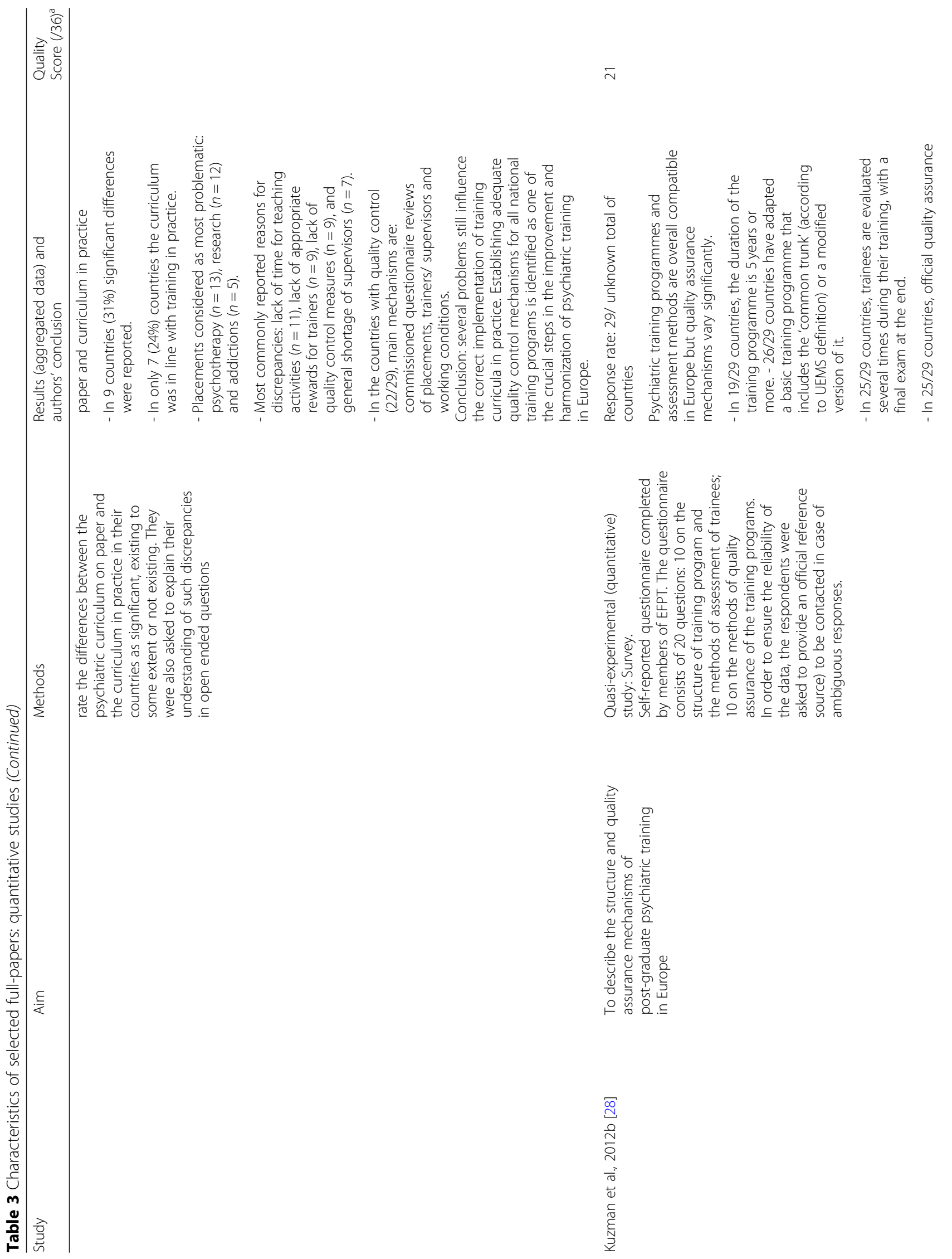




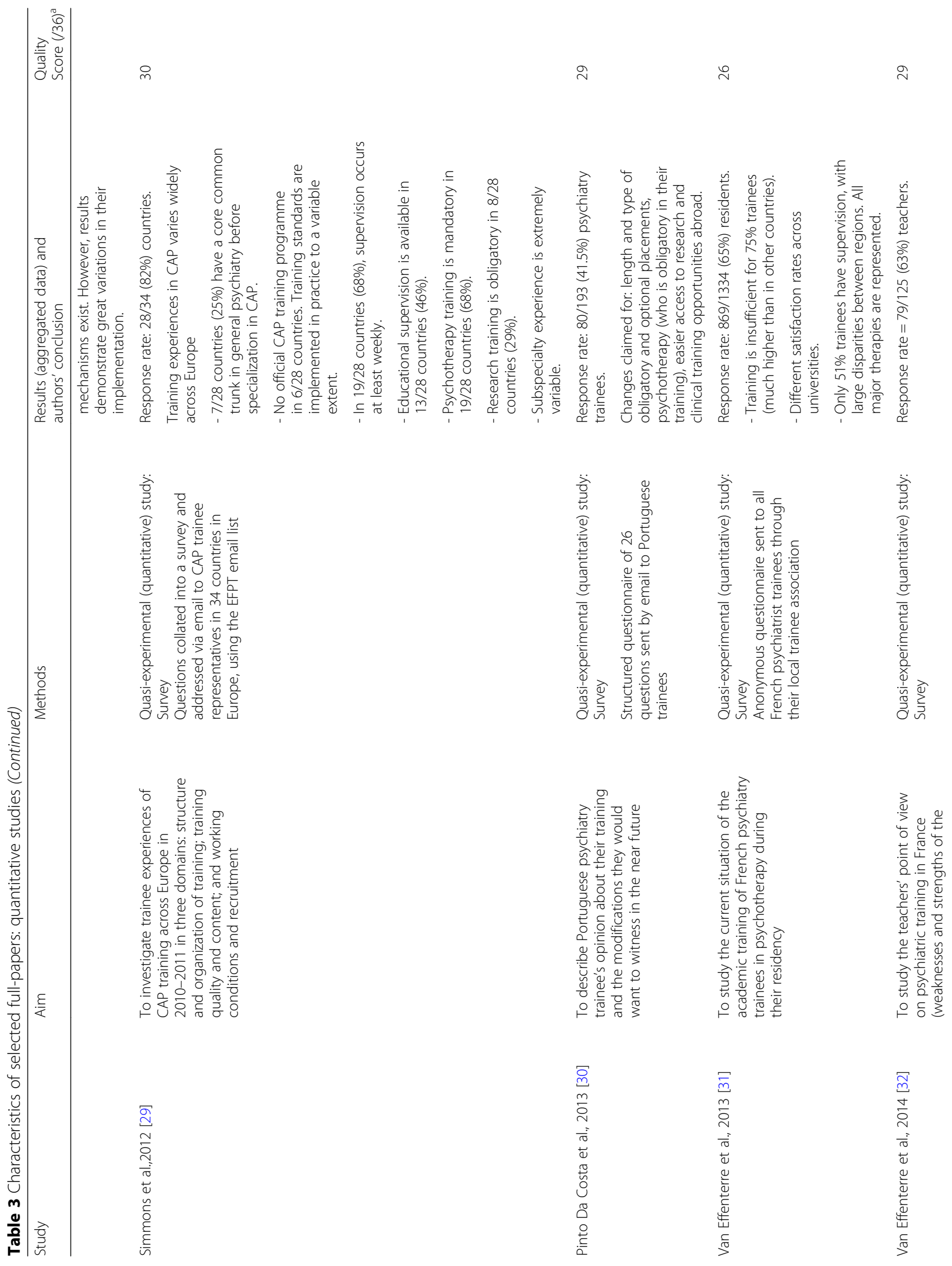




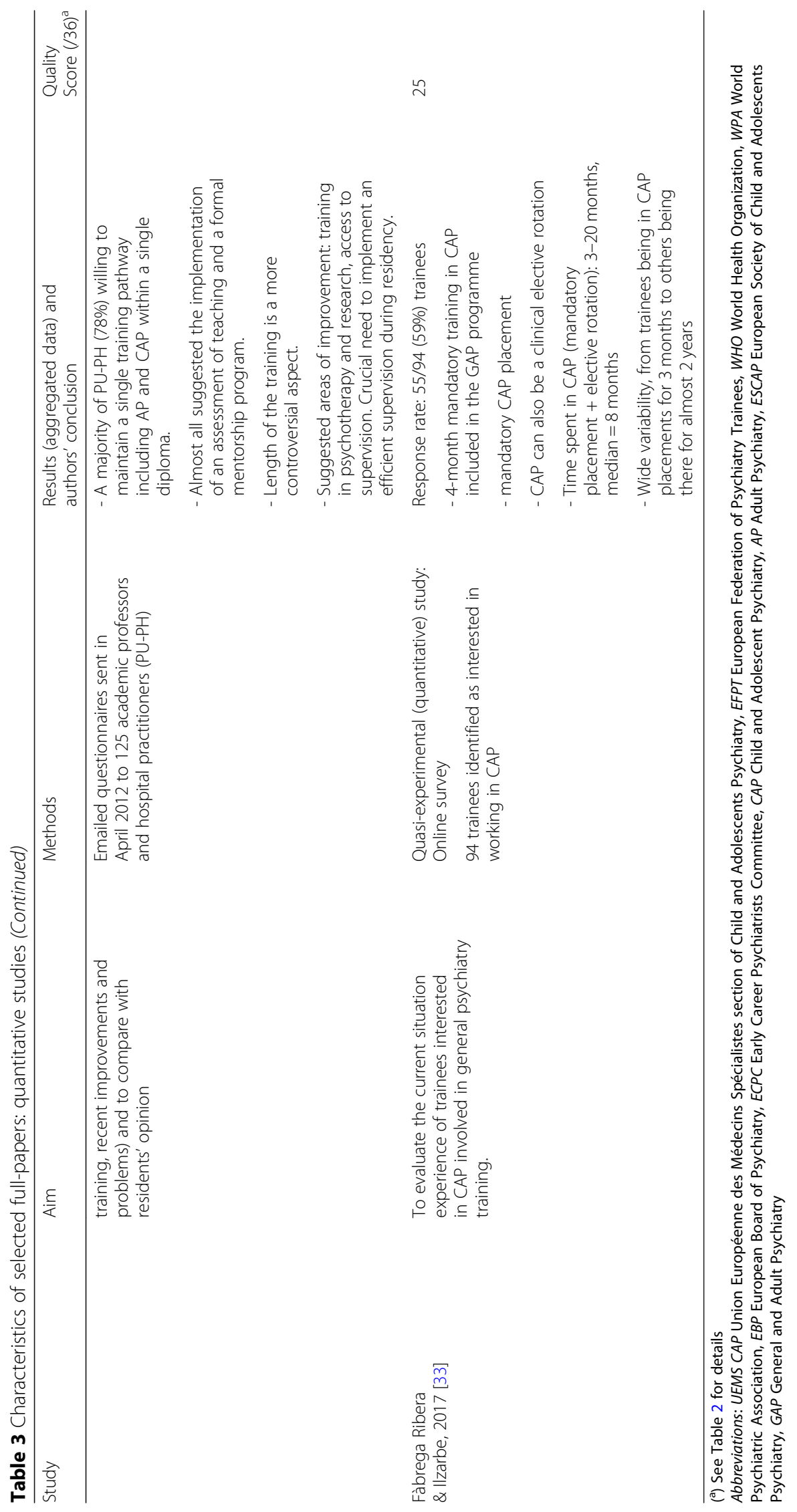




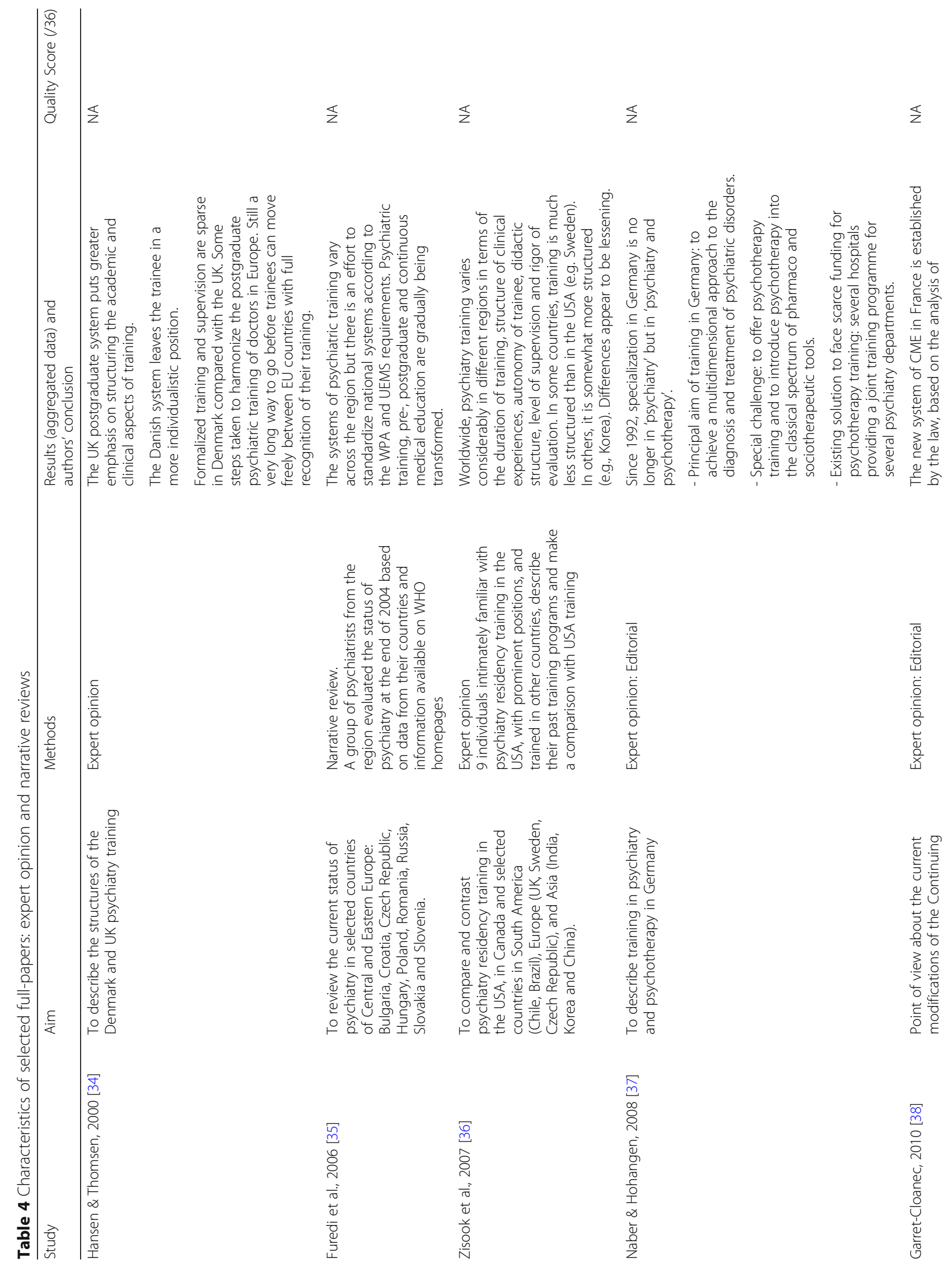




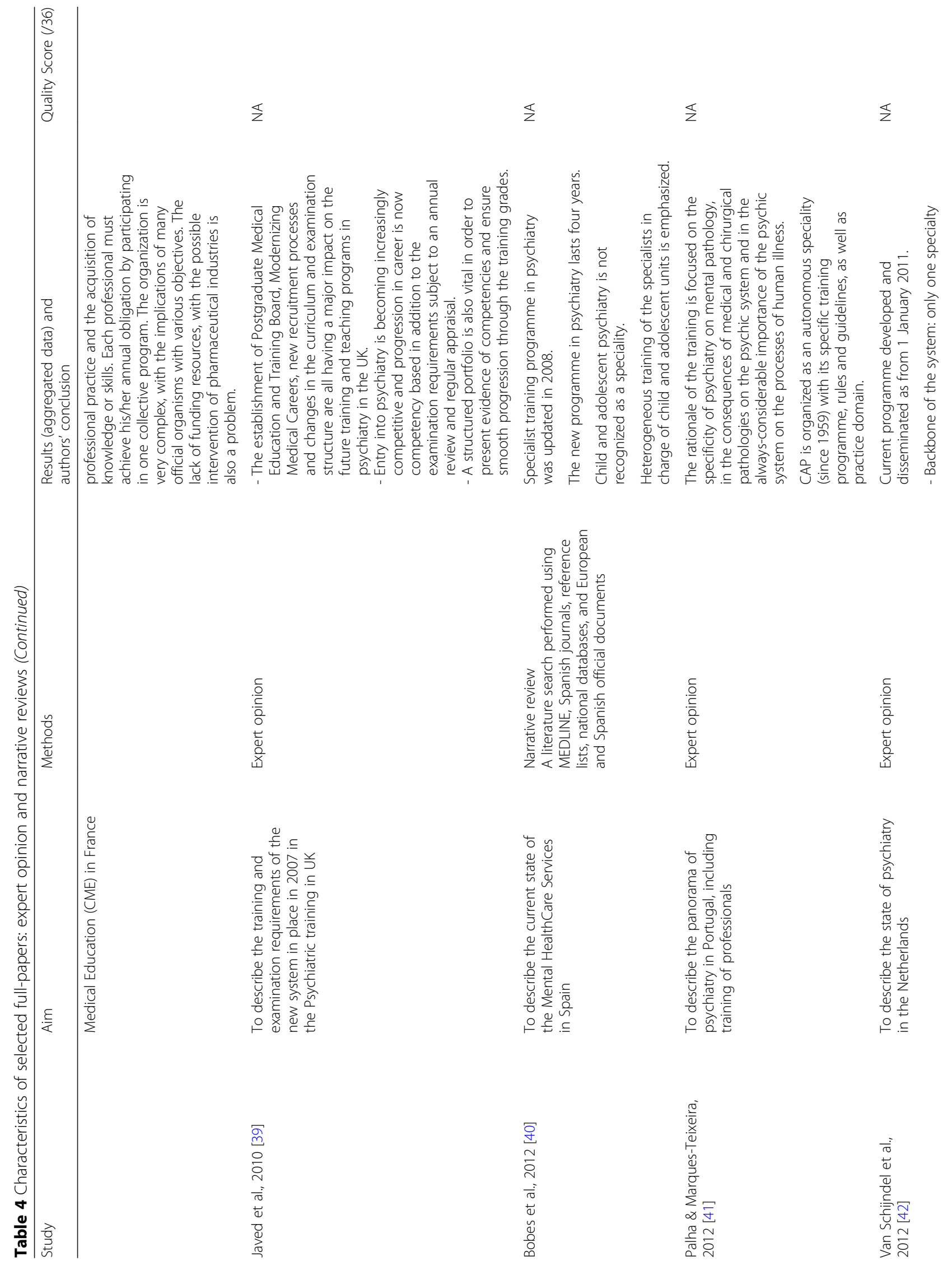


Russet et al. BMC Medical Education

(2019) 19:204

Page 14 of 27

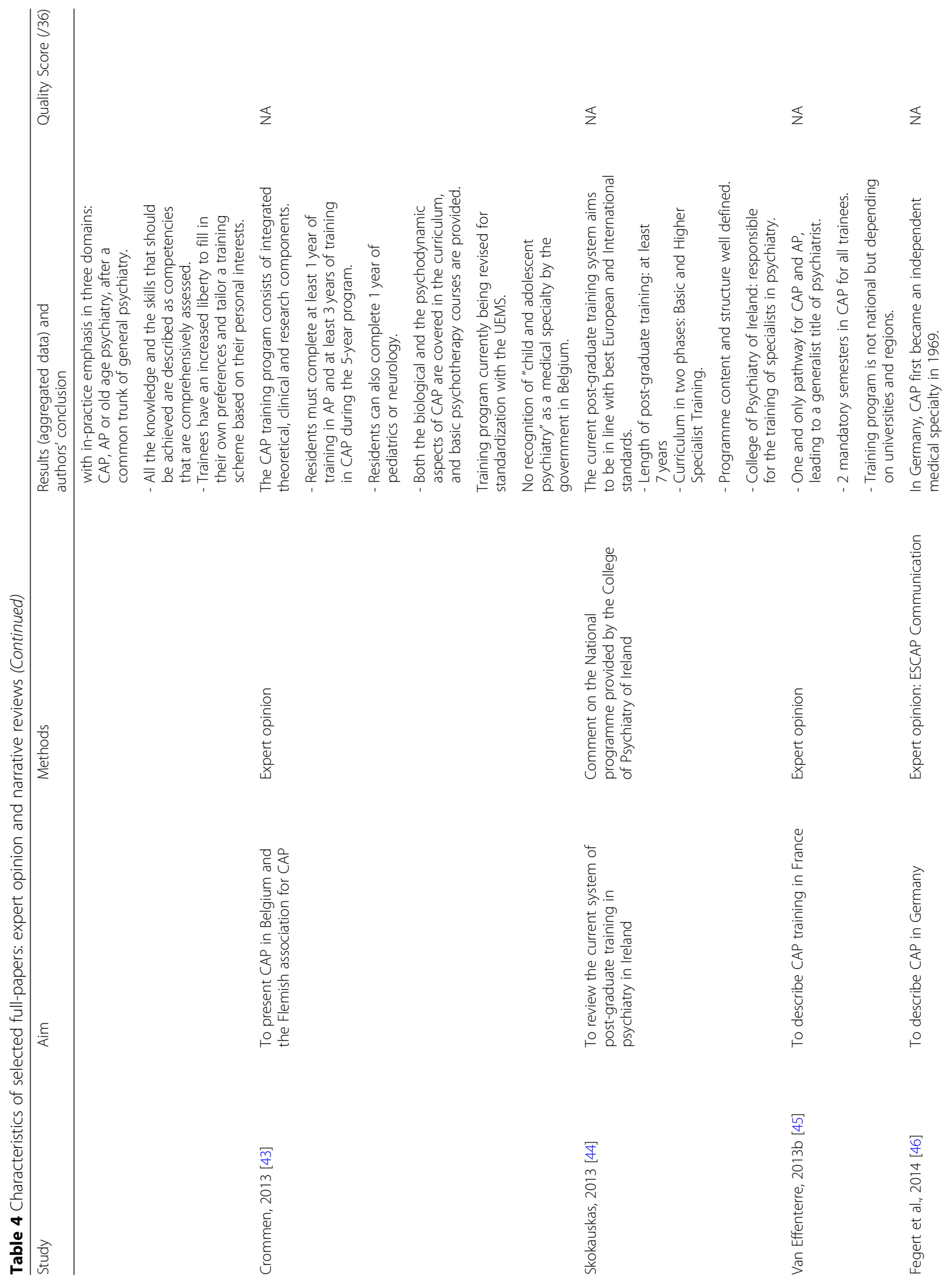




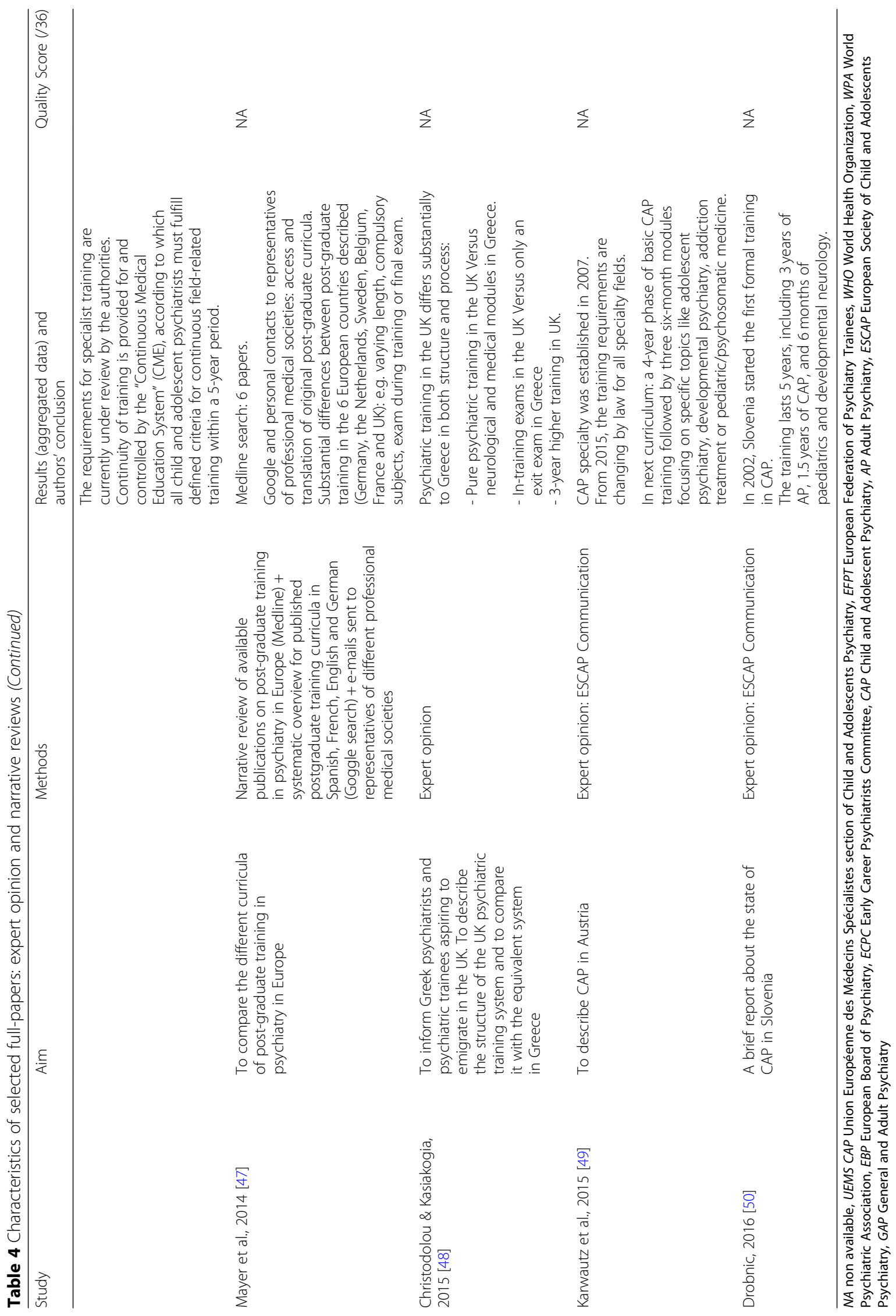




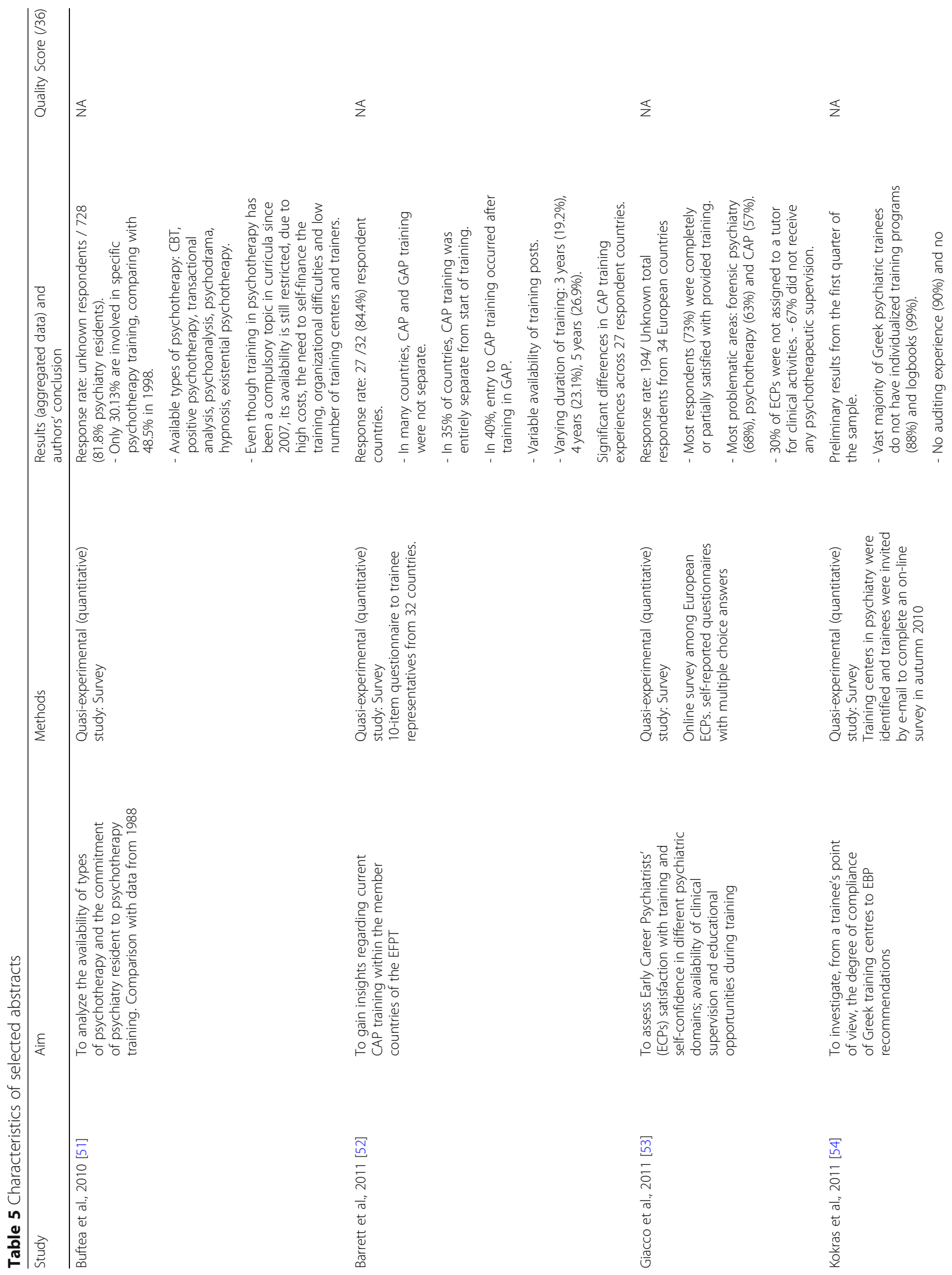




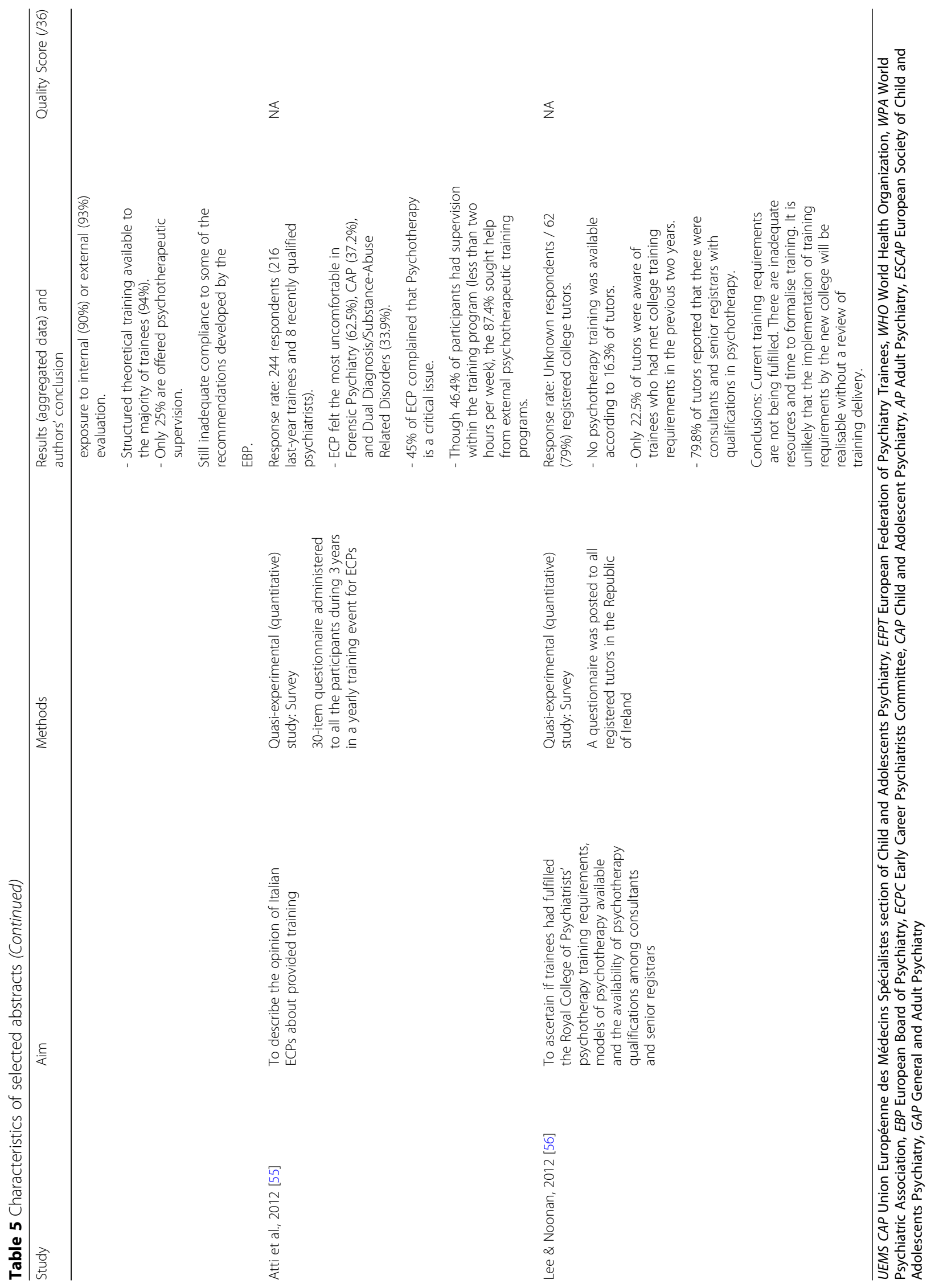


Table 6 General Adult Psychiatry training in Europe - synthesis of collected data

\begin{tabular}{|c|c|}
\hline General Adult Psychiatry training & $\begin{array}{l}\text { Number / number } \\
\text { of known data (\%) }\end{array}$ \\
\hline \multicolumn{2}{|l|}{ National standardized training program } \\
\hline Y & 19 / 24 (79\%) \\
\hline \multicolumn{2}{|l|}{ Quality control of the training program } \\
\hline \multicolumn{2}{|l|}{ Presence } \\
\hline Y & 20 / 23 (87\%) \\
\hline \multicolumn{2}{|l|}{ Realized by } \\
\hline $\begin{array}{l}\text { ministry of health or national } \\
\text { board }\end{array}$ & $16 / 23(70 \%)$ \\
\hline regional or university & $3 / 23(13 \%)$ \\
\hline both & $1 / 23(4 \%)$ \\
\hline \multicolumn{2}{|l|}{ Program length (years) } \\
\hline$<4$ & 3 / 34 (9\%) \\
\hline $4 \leq \leq 6$ & 26 / $34(76 \%)$ \\
\hline$>6$ & $0 / 34$ \\
\hline Contradictory & $5 / 34(15 \%)$ \\
\hline \multicolumn{2}{|l|}{ Assessment } \\
\hline \multicolumn{2}{|l|}{ Presence } \\
\hline Y & 25 / $32(78 \%)$ \\
\hline during training & $3 / 32(9.5 \%)$ \\
\hline $\begin{array}{l}\text { during training and final board } \\
\text { exam }\end{array}$ & $19 / 32(59 \%)$ \\
\hline final board exam & $3 / 32(9.5 \%)$ \\
\hline $\mathrm{N}$ & $1 / 32(3 \%)$ \\
\hline Contradictory & $6 / 32(19 \%)$ \\
\hline \multicolumn{2}{|l|}{ Realized by } \\
\hline supervisor only & 10 / 28 (36\%) \\
\hline board commission & $2 / 28(7 \%)$ \\
\hline WBA & $4 / 28(14 \%)$ \\
\hline $\begin{array}{l}\text { supervisor and board } \\
\text { commission }\end{array}$ & $6 / 28(21 \%)$ \\
\hline supervisor and WBA & $5 / 28(18 \%)$ \\
\hline $\begin{array}{l}\text { supervisor, board commission } \\
\text { and WBA }\end{array}$ & $1 / 28(4 \%)$ \\
\hline \multicolumn{2}{|l|}{ Logbook } \\
\hline Y & 23 / 28 (82\%) \\
\hline \multicolumn{2}{|l|}{ Consequences } \\
\hline Y & 18 / 25 (72\%) \\
\hline
\end{tabular}

Compulsory common trunk of fundamental knowledge (UEMS 2003) General adult psychiatry

Y

$28 / 28(100 \%)$

CAP, learning difficulties and mental handicap

Y

$27 / 28(96 \%)$

Old age psychiatry

Y
Table 6 General Adult Psychiatry training in Europe - synthesis of collected data (Continued)

\begin{tabular}{|c|c|}
\hline General Adult Psychiatry training & $\begin{array}{l}\text { Number / number } \\
\text { of known data (\%) }\end{array}$ \\
\hline \multicolumn{2}{|l|}{ Addictions } \\
\hline Y & 28 / 29 (97\%) \\
\hline \multicolumn{2}{|l|}{ Forensic psychiatry } \\
\hline Y & $23 / 26(88 \%)$ \\
\hline \multicolumn{2}{|l|}{ Psychotherapy } \\
\hline Y & 19 / 29 (66\%) \\
\hline $\mathrm{N}$ & $7 / 29(24 \%)$ \\
\hline Contradictory & $3 / 29(10 \%)$ \\
\hline \multicolumn{2}{|c|}{ Compulsory common trunk of skills (UEMS 2003) } \\
\hline \multicolumn{2}{|l|}{ In-patient psychiatry } \\
\hline Y & 27 / $27(100 \%)$ \\
\hline \multicolumn{2}{|l|}{ Out-patient psychiatry } \\
\hline Y & $28 / 28(100 \%)$ \\
\hline \multicolumn{2}{|c|}{ Liaison and consultation psychiatry } \\
\hline Y & 15 / $27(55 \%)$ \\
\hline $\mathrm{N}$ & $11 / 27(41 \%)$ \\
\hline Contradictory & $1 / 27(4 \%)$ \\
\hline \multicolumn{2}{|l|}{ Emergency psychiatry } \\
\hline Y & 27 / $27(100 \%)$ \\
\hline \multicolumn{2}{|l|}{ Compulsory training } \\
\hline \multicolumn{2}{|l|}{ Neurology } \\
\hline Y & 13 / 14 (93\%) \\
\hline \multicolumn{2}{|l|}{ Internal medicine } \\
\hline Y & 10 / 12 (83\%) \\
\hline
\end{tabular}

Abbreviations: $Y$ yes, $N$ no, WBA workplace based assessment, UEMS Union Européenne des Médecins Spécialistes

registered college tutors in Ireland just prior to the College of Psychiatry of Ireland setting out psychotherapy training requirements: $16 \%$ of tutors reported that no psychotherapy training was available for the trainees, and only $22.5 \%$ of tutors were aware of trainees who had met college training requirements in the previous two years.

* There were major variations in supervision during speciality training, even within countries. Supervision was compulsory in Estonia [23], Germany [23, 47], Sweden [36, 47] and the UK [20]. It was optional in France [31] and Greece [54]. Data were contradictory for Italy: according to Oakley [23] it was compulsory for all, but Atti [55] indicated this to be the case for only $46 \%$ of trainees. Two types of supervision were commonly reported: clinical supervision in Estonia [23], Germany [23, 47], Sweden [36, 47], Greece [54], Italy [23], UK [58]; and educational supervision in Sweden [36, 47], UK [20] and Ireland [59]. Whatever 
the type of supervision, access was not always guaranteed for the trainees, evident in Italy [55] and Greece [54].

* Data about research training were scarce. Trainees in Belgium and the Netherlands were required to have at least one publication in a peer-reviewed journal [47]. Research training was optional in both France [26] and Portugal [30]. No scheduled time for research was available in Denmark [34].

* Continuing Medical Education (CME) was reported as mandatory in Germany [47], Hungary, Russia and Slovakia [35], France [36], with regular compulsory recertification in Croatia [35], the Netherlands [47] and Poland [35]. This was also the case in Czech Republic but without specified sanctions in case of noncompliance [35]. CME was reported as optional in Bulgaria [35]; No data regarding CME was found for the other countries.

\section{Child and adolescent psychiatry (CAP)}

Available data for CAP in each European country are summarized in Table 7 (detailed in Additional file 4: Table S5 and Additional file 5: Table S6). When aggregated data (not specifically detailed for each country) are reported in the text here below, the reference of the corresponding paper is provided.

CAP and GAP training were delivered separately at the start of training in more than half of the European countries; yet for a further $21 \%$ of countries, this relationship could not be precisely determined due to contradictory data available (Czech Republic, Estonia, Latvia and UK) (Additional file 4: Table S5) or because the term "separate" is not defined in the available literature. The case of Spain is particular: CAP and GAP are now separated according to the Law but this separation has not been implemented yet, leading to still one common training [33].

Out of the 27 countries for which data was provided, $85 \%$ of European countries had a standardized CAP theoretical program. However, fully implemented national training standards were identified in only $34 \%$ of countries. The total length of training required for becoming a CAP specialist ranged from 4 to 6 years for $73 \%$ of countries, including a period between 2 and 4 years dedicated specifically to CAP for $66 \%$ of these countries.

In CAP training, the mean duration of compulsory time spent in CAP and Adult Psychiatry (AP) placements was 38 months and 13 months, respectively [23]. Training and experience in child neurology, paediatrics and neurology were required in 42, 64 and 59\% of countries, respectively, but content and duration were rarely specified for these topics. More details were available concerning psychotherapy. Training in psychotherapy involved theory and practice in $92 \%$ of countries. It included CBT in $100 \%$ of countries and systemic and psychodynamic therapies in respectively 81 and $86 \%$. It was mandatory in $41 \%$ of countries.

Supervision was available in $93 \%$ of countries. As regards the types of supervision, trainees had access to independent educational supervision in only $44 \%$ of countries. No data were found for other types (e.g. clinical supervision). Frequency of supervision varied between countries: it occurred weekly in 19/28 (68\%) countries, or alternatively daily or every few months [29]. Research experience was not compulsory in $58 \%$ of the countries.

Finally, assessment methods varied widely, with oral exams in $19 / 28$ (68\%), workplace assessments in $16 / 28$ (57\%) and written exams in 12/28 (43\%) countries [29]. Compared with GAP, no data about CME was available, except for Germany [46].

\section{Transition in GAP and CAP programmes}

Only two countries mentioned transition in their programmes: UK and Ireland. However, no specific mention was found in the GAP section: either for Ireland, or for UK in the Curriculum for Specialist Training in General Psychiatry [58] or in the Curriculum for the Core Training [60]. Transition was only addressed in CAP programmes. In the UK, it was mentioned in the Curriculum for Specialist Training in CAP (ST4-6/ Higher training) [61]. In the mandatory part of the training, it was briefly referred to in connection with assessing and managing main clinical diagnoses in adolescence and future outcomes, and working in collaboration with children/young people and families and appropriate teams. The skills section was more specific and outlined a practical step to be taken when facilitating transitioning care from CAMHS, i.e. preparing transition plans taking account of local protocols. An optional learning objective linked with transition was also available, providing more details regarding various aspects of transition. In Ireland, transition was mentioned briefly in the CAP section of the Curriculum for basic and higher specialist training in psychiatry [59], advising that Case Based Discussion should be applied when managing transition of an adolescent to an adult mental health service.

\section{Discussion}

The aim of this review was to determine current training programmes in General Adult Psychiatry and Child and Adolescent Psychiatry across Europe and to assess if and how transition as a topic is incorporated in the training curricula of these disciplines. A systematic review was conducted and provided 45 documents. 
Table 7 Child and Adolescent psychiatry training in Europe synthesis of collected data

\begin{tabular}{|c|c|}
\hline Child and Adolescent Psychiatry training & Number / number of known data (\%) \\
\hline \multicolumn{2}{|l|}{ Separate training of CAP and GAP } \\
\hline Y & $21 / 33(64 \%)$ \\
\hline from start of training & $18 / 33(55 \%)$ \\
\hline after common trunk with GAP & $3 / 33(9 \%)$ \\
\hline N & $5 / 33(15 \%)$ \\
\hline Contradictory or not specified & $7 / 33(21 \%)$ \\
\hline \multicolumn{2}{|l|}{ Is CAP a monospecialty / separate specialty? } \\
\hline Y & 24 / $34(71 \%)$ \\
\hline \multicolumn{2}{|l|}{ National training standards } \\
\hline Y & $26 / 29(90 \%)$ \\
\hline fully implemented & $10 / 29(34 \%)$ \\
\hline implemented in part & $15 / 29(52 \%)$ \\
\hline not implemented & $1 / 29(4 \%)$ \\
\hline \multicolumn{2}{|l|}{ Is there a CAP theoretical program? } \\
\hline Y & $23 / 27(85 \%)$ \\
\hline with standardized content & $10 / 27(37 \%)$ \\
\hline without standardized content & $13 / 27(48 \%)$ \\
\hline N & $3 / 27$ (11\%) \\
\hline Contradictory & $1 / 27(4 \%)$ \\
\hline
\end{tabular}

Program length (total minimum after medical school to be a CAP specialist, in years)
$<4$
$3 / 34(9 \%)$
$4 \leq \leq 6$
$25 / 34(73 \%)$
$>6$
$4 / 34(12 \%)$
Contradictory
$2 / 34(6 \%)$

Minimum duration specifically dedicated to CAP during this program (years)
$<2$
$2 / 33(6 \%)$
$2 \leq<3$
$10 / 33(30 \%)$
$3 \leq<4$
$12 / 33(36 \%)$
$\geq 4$
Contradictory
4 / 33 (12\%)
5 / $33(15 \%)$

Supervision

Access to formal supervision

$25 / 27(93 \%)$

Independent educational supervision

12 / $27(44 \%)$

Assessment

$\begin{array}{ll}\text { Logbook } & 22 / 31(71 \%) \\ \text { Examination to be a trainee in CAP } & 12 / 30(40 \%) \\ \text { Examination to finish the training in CAP } & 22 / 34(65 \%) \\ \text { Duration of inpatient experience (months) } & \\ <12 & 5 / 27(18 \%) \\ 12 \leq \leq 24 & 11 / 27(41 \%) \\ >24 & 10 / 27(37 \%) \\ \text { Contradictory } & 1 / 27(4 \%)\end{array}$

Duration of outpatient experience (months)
$<12$
$8 / 27$ (30\%)
$12 \leq \leq 24$
$11 / 27(41 \%)$
$>24$
$7 / 27$ (26\%)
Contradictory

Table 7 Child and Adolescent psychiatry training in Europe synthesis of collected data (Continued)

\begin{tabular}{|c|c|}
\hline Child and Adolescent Psychiatry training & Number / number of known data (\%) \\
\hline \multicolumn{2}{|l|}{ General adult psychiatry training } \\
\hline Y & $28 / 31$ (91\%) \\
\hline mandatory & $26 / 31(83 \%)$ \\
\hline optional & $2 / 31(6 \%)$ \\
\hline $\mathrm{N}$ & $1 / 31(3 \%)$ \\
\hline Contradictory & $2 / 31(6 \%)$ \\
\hline \multicolumn{2}{|l|}{ Child neurology training } \\
\hline Y & $21 / 31(68)$ \\
\hline mandatory & $13 / 31(42 \%)$ \\
\hline optional & $8 / 31(26 \%)$ \\
\hline Not needed ${ }^{a}$ & $10 / 31(32 \%)$ \\
\hline \multicolumn{2}{|l|}{ Paediatric experience } \\
\hline Y & $21 / 33(64 \%)$ \\
\hline mandatory & $14 / 33(43 \%)$ \\
\hline optional & $3 / 33(9 \%)$ \\
\hline not specified & $4 / 33(12 \%)$ \\
\hline Not needed ${ }^{\mathrm{a}}$ & $7 / 33(21 \%)$ \\
\hline Contradictory & 5 / $33(15 \%)$ \\
\hline \multicolumn{2}{|l|}{ Neurology experience } \\
\hline Y & 16 / 27 (59\%) \\
\hline mandatory & $4 / 16(25 \%)$ \\
\hline optional & $2 / 16(12.5 \%)$ \\
\hline not specified & $10 / 16(62.5 \%)$ \\
\hline $\mathrm{N}$ & $10 / 27(37 \%)$ \\
\hline Contradictory & $1 / 27(4 \%)$ \\
\hline
\end{tabular}

Psychotherapy training

Presence

\begin{tabular}{|c|c|}
\hline Y & $20 / 34(59 \%)$ \\
\hline mandatory & $14 / 34$ (41\%) \\
\hline optional & $6 / 34(18 \%)$ \\
\hline Not needed ${ }^{\mathrm{a}}$ & $7 / 34(20.5 \%)$ \\
\hline Contradictory & $7 / 34(20.5 \%)$ \\
\hline \multicolumn{2}{|l|}{ Program structure } \\
\hline Theoretical \& practical & 24 / $26(92 \%)$ \\
\hline Theoretical only & $4 / 26(8 \%)$ \\
\hline \multicolumn{2}{|l|}{ Type } \\
\hline CBT & $21 / 21(100 \%)$ \\
\hline systemic & $17 / 21$ (81\%) \\
\hline psychodynamic & $18 / 21(86 \%)$ \\
\hline other & $5 / 21(24 \%)$ \\
\hline \multicolumn{2}{|c|}{ esearch experience compulsory? } \\
\hline & $6 / 33(18 \%)$ \\
\hline v & $19 / 33(58 \%)$ \\
\hline Contradictory & $8 / 33(24 \%)$ \\
\hline
\end{tabular}




\section{Current GAP and CAP training in Europe: the issue of harmonization}

A key objective of the European Economic Community is to allow the free movement of professionals (Treaty of Rome, 1957). Hence, one of the major challenges concerning psychiatry in Europe has been the harmonization of training and certification requirements. Various professional organizations have been working for 20 years on recommendations to harmonize an optimal quality of national psychiatry training programs in Europe $[62,63]$.

According to data collected through our review, this harmonization has reached a significant level on several aspects of both GAP and CAP trainings: national programs, program length (in the average range of 4-6 years for about 3/4 of countries), mandatory GAP training in CAP and mandatory CAP training in GAP. For GAP training in particular, quality control of the training programs implementation is reported in most countries. For CAP, supervision in general is widely accessible in the vast majority of countries.

However, harmonization is still to be achieved on several other aspects. Most importantly, in both CAP and GAP trainings, differences between the stated national programmes and the lived experience of trainees are reported, suggesting substantial variations at a local level $[20,29,63]$. For both, there is still no final board exam in $1 / 3$ of countries and no mandatory training in psychotherapy in $1 / 3$ or even more for CAP. As regards data available for GAP more specifically, crucial aspects of the compulsory common trunk of knowledge and skills defined by UEMS [13] like old age psychiatry or liaison and consultation psychiatry are still not mandatory (respectively, in 31 and $41 \%$ of countries) ${ }^{1,2}$. In terms of examination and assessment methods, there is still no consequence in case of failed assessment in $28 \%$ of countries. Concerning assessment methods in particular, a most interesting evolution is taking place but is still restricted to a few countries like UK [64] or the Netherlands [42]: a shift from a system based only on participation of the trainee towards a "competence-based training" model where trainees are much more responsible and skills are central. Finally, very scarce data about CME show that few countries keep a register or set minimum standards [65] and that there are important variations in modalities [35, 36, 47]. For CAP, available data show harmonization is not yet realised regarding the access to an independent educational supervision.

As a major manifestation of this harmonization still to be achieved, we delineated 3 coexisting models of training and practice of GAP and CAP in Europe (Fig. 2). In the first model, psychiatry is a general speciality, with possible subspecialties that are not mandatory. Trainees are provided with a generalist education and receive a general diploma of "psychiatrists". This model was identified only in $5 / 33$ countries $(15 \%)^{3}$, among which Spain was included since the separation of GAP and CAP has not been implemented in the training programmes yet [33]. In the second model, psychiatry is divided into totally independent specialties (e.g. CAP, AP, forensic, addictions, old age, etc). Trainees are provided with a separate specialized training from the start after medical studies, with completely different programs. This model is common and prevalent in $18 / 33$ countries $(55 \%)^{4}$. Finally, 5/33 countries $(15 \%)^{5}$ countries used a third model, where trainees were provided with a common specialist psychiatry core program followed by further specialization - this often led to longer total training periods. Five remaining countries $(15 \%)^{6}$ could not be classified, due to unclear or contradictory data.

\section{Transition as a topic in training of CAP and GAP in Europe}

This review identified only two countries where this topic appeared in the curricula. In Ireland and the UK, transition has recently become a mandatory topic, but it is only covered briefly in the training documentation (in the UK, however, an elective course provides also more detailed training). Furthermore, transition is only addressed in CAP training, with no mention of it in GAP training. Likewise, training in transition has been newly identified by the UEMS as part of the goals that should be acquired by trainees, but this is limited to CAP in the interim $[66,67]$. It is important to note that both Ireland and the UK fall into the third model, which involves long periods in training and possibly allows for varied topics to be covered, including transition as a topic.

Outside Europe, authors from Australia, Canada and the United States (US) have identified difficulties in access to care and coordinated services for youth with mental health conditions [68-71]. Training in transitional care has also been identified as a strategy to aid continuity of care and support for different domains of functioning in young people with mental health conditions. Cross-training about transition in mental health where adult and child case managers are trained together has been documented in 19 out of 50 states in the US [72] and a systems of care guidelines for transition-aged youth has been provided [73].

Within the MILESTONE-project training material about transition in mental health conditions will be delivered. These training modules are intended for health care professionals, stake-holders and for the general public and will be made available on the project website: www.milestone-transitionstudy.eu. In France, a specific training module has recently been added in the revised mandatory national curriculum of trainees in psychiatry https://sides.uness.fr/. 


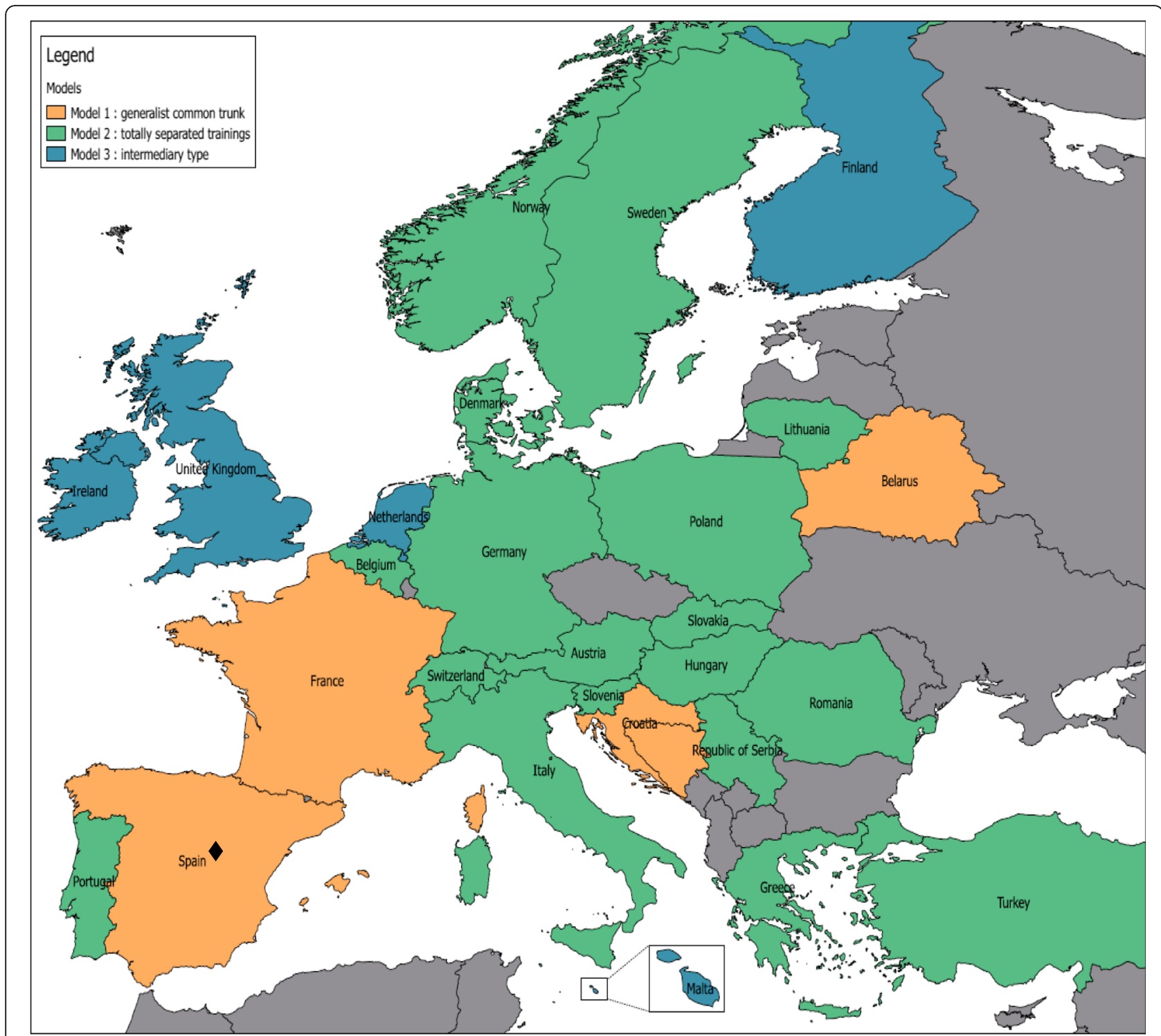

In spite of the existing law introducing separated training for CAP and GAP, Spain was maintained in the Model 1 because this law has not been implemented yet

Fig. 2 Mapping of 3 coexisting models of training and practice of GAP and CAP in Europe

Facilitators and/or barriers to transition in training - avenues Relationships between GAP and CAP are a crucial issue in the transition process, both in terms of the experience that professionals have of the other discipline and in terms of common knowledge allowing a better dialogue and collaboration. Data collected in this review are reassuring from this point of view: $83 \%(26 / 31)$ of CAP training programs required a compulsory period of training in GAP and $96 \%(27 / 28)$ of GAP training programs required a compulsory period of training in CAP (Tables 6 and 7). However, the real length of exposure to the other discipline and content of training is variable and should be specifically explored in further studies.

Crucial structural differences in training models should be taken into account, as they probably have an impact on the relationships between both specialities. Thus, the monospeciality type of training (model 2) may significantly reduce the training in CAP for those who choose GAP specialty, and vice versa. Separate training pathways with no common basis, and often with no training provided in the other speciality (e.g. Germany), may contribute to a fragmented understanding of, and less experience in developmental psychopathology. 
While adolescence is a crucial period in the emergence of psychopathology and onset of disorders, trainees undergoing GAP training in this model may end up with a lack of knowledge and understanding of developmental psychopathology. The generalist type of training (model 1) and the common core program with further mandatory specialization (model 3) appear to better guarantee a more balanced experience in both specialities during the whole postgraduate training. These two models may also guarantee a better cooperation between child and adult psychiatrists when young service users face transition. The generalist training should, nevertheless, be long enough to allow a real core training in which CAP occupies a significant part of the curriculum. In its publications, the MILESTONE group have started examining the influence of the different training models on the transition outcome of young people in the MILESTONE study, combining European mapping data of child and adolescent mental health services with data on training models [74].

\section{How can training programs ensure improved quality of transition?}

First, in order to improve the quality of care in transition, both CAP and AP training programs should definitely start including transition as a mandatory subject. This is the direction currently followed by professional organizations: the two corresponding sections of UEMS have recently been involved in discussions regarding transition and a joint working group has been set up to look at transition from child to adult services [66, 74]. Fegert et al. (2017) mention "transition psychiatry" as a topic to be established both in training and continuous medical education, to compensate for a missing expertise $[67,75]$.

Second, the content of training must be reviewed. A structured and evidence-based training to transition, related to skills, should be provided as a priority. The TRACK study [1] suggested four major criteria for an optimal transition in mental health care, which could act as a starting point for training in transition: 1) 'Continuity of care', 2) 'Period of parallel care (relational continuity)', i.e. a period of joint working where the service user is involved with both CAMHS and AMHS; 3) 'Transition planning meetings' (cross-boundary and team continuity)', i.e. at least one meeting discussing the transition from CAMHS to AMHS, involving the service user and/or carer and key professionals, prior to the handover of care from CAMHS to AMHS; 4) 'Optimal information transfer (information continuity)', i.e. referral letter, summary of CAMHS contact, any or all CAMHS notes and a contemporary risk assessment.

Beyond the transition as a topic in itself, developing other specific related topics is also crucial: 1) promoting a life span concept of the patient, like in the USA where training about child and adult development is available during the core training [36]; 2) extending this developmental approach particularly in GAP training $[8,76,77]$, giving trainees mandatory experience across ages [64]. This is particularly needed for neurodevelopmental disorders like Attention-Deficit Hyperactivity Disorder [78] or Autism Spectrum Disorder, which are now well known to go on far beyond childhood and adolescence. 3) The specific needs and issues of adolescents and young adults should also be emphasized, as has already been done for the elderly in many countries (without necessarily making it a specialty in itself). The care for young people should be more comprehensive, or far-reaching, and take into account potential school problems, autonomy, support and involvement of parents, professional involvement, all of which necessitate collaboration between professionals and developing partnerships. For many years now, somatic medicine has emphasised this necessary focus on adolescents and their specific needs $[7,9,77,79]$. A position paper about transitional care in adolescents with chronic conditions published by the Society of Adolescent Medicine has identified environmental support, decision-making and consent, family support and professional sensitivity to psychosocial issues as key factors for a successful transition [80]. Therefore, training in transition care should not only be a symptoms-based approach but a comprehensive developmental approach. Health providers in both paediatric and adult settings should be trained in shared case management. Contents of training should include the development of decision-making skills in adolescents during the transition process as well as family support because some parents will need the help of health providers to adjust to the changing needs of their children. In a study about parent perspectives, family members of young people with mental health conditions requested service providers to consider them as resources and potential collaborators in supporting young people in transition to live successful lives in the community [81].

Third, what is the best timing and manner for delivering training on transition and other relevant topics? A minimum mandatory content regarding transition should be included in training (in theoretical courses or in case studies). CME could be another opportunity for training in transition, provided that relevant modules are available. Developing a CME training programme in transition is one of the objectives of the MILESTONE Project. Joint training events between CAMHS and AMHS professionals could also be an avenue, particularly because they have been shown to improve working relationships and create opportunities for collaborative work [82-84]. 


\section{Limitations}

As regards the critical analysis of papers selected in our systematic review, several aspects should be taken into account when considering the results. Half of the references were expert papers, narrative reviews and other documents of the grey literature. Therefore, our review suffers from limitations usually related to the very nature of these documents (e.g. non-representative samples of studies, lack of quality appraisal, and multiple citation bias). The formal quality appraisal of the quantitative studies yielded low scores in sampling and data analysis as well as in ethics/bias assessment. Transferability/ generalizability was questionable due to the type of data collection. Indeed, trainees were the only source of information in a majority of the studies (17/22, 77\%). This participant selection may have impacted the quality of the reported information because trainees may not be aware of every aspects of the official curricula and may rely on limited experience within their own training centres. Our review also suffers from database and language biases because certain national journals may have been underrepresented in the databases we used and because of exclusion of a limited amount of studies in other languages that English or Spanish.

Some data were not available for all countries, making comparisons difficult when exploring the harmonization process. In addition, the number of references on CAP and GAP training varied widely between countries, from one to more than six references per discipline and country. Most countries (68\% for CAP and $86 \%$ for GAP) had between two to five references per discipline (Additional file 2: Table S3, Additional file 3: Table S4, Additional file 4: Table S5 and Additional file 5: Table S6). More specifically, scarce (information obtained for $<5 / 19$ items) or no data was available for $9 / 35^{1}$ countries regarding GAP, and for $6 / 35^{2}$ countries regarding CAP. Some essential issues were poorly covered: minimum length of training in psychotherapy, research, exact content of theoretical education, time dedicated to the different disciplines, continuing medical education.

Contradictory data were found in 5/19 items for GAP training and 10/19 items for CAP training (e.g. duration of GAP training in France was six years according to Kuzman [28] and four years according to Mayer [47]). This was particularly significant (with more than $10 \%$ of contradictory data) for program length (GAP and CAP training), assessment, and mandatory psychotherapy (GAP training), separate GAP and CAP training, paediatric experience, and psychotherapy training (CAP training) (Additional file 2: Table S3, Additional file 3: Table S4, Additional file 4: Table S5 and Additional file 5: Table S6). Lack of precise definitions of terms used in questionnaires may have contributed to this, leading to unclear or imprecise questions and/or answers (e.g. what is meant by the word "speciality", or "separate training"). Another limitation is that the degree of implementation of national programs was not measurable, as this aspect were not systematically analysed at both national and local levels.

Finally, this review focusses on psychiatry but it must be kept in mind that other mental health disciplines are also involved in transition (i.e. psychologists, behavioural therapists and psychotherapists, psychiatric nurses, paediatricians). The training of professionals in these disciplines should be explored in relation with transition as well.

\section{Strengths}

Our systematic review of literature aimed at minimizing bias and reducing subjectivity by usage of inclusion/exclusion criteria and of a formal quality appraisal. Interpretation bias was also limited by the different background of the researchers. Among the twenty-three questionnairebased surveys (abstracts and full text altogether) seventeen reported response rates (Tables 3, 4 and 5), most of which can be considered good: between 60 and $80 \%$ in $6 / 16(37 \%)$ surveys and equal or more than $80 \%$ in $7 / 16(44 \%)$.

\section{Conclusion}

To the best of our knowledge, this is the first systematic review on General Adult Psychiatry and Child and Adolescent Psychiatry training in Europe. It is also the first to focus on transition as a topic in training programs. Three coexisting models of training in GAP and CAP across Europe have been identified, indicative of a harmonization still in progress. As these three models do not allow the same level of collaboration between GAP and CAP professionals, it is a possible barrier to a good quality or smooth transition. Future studies on the content, quality and experience of training should focus on including all key stakeholders involved in psychiatry programs (i.e. not only trainees, but also early career psychiatrists, professors and representatives of national professional organisations). Although probably a crucial element for ensuring optimal transition of mental health service users, transition as a topic in training is only beginning to be considered. We have suggested several avenues to foster this trend. The increasing common reflection between both specialities and sub-specialities is a promising move towards further positive developments.

\section{Endnotes}

${ }^{1}$ Albania, Moldavia, Luxembourg, Cyprus, Montenegro, Iceland, Bulgaria, Hungary, Norway.

${ }^{2}$ Moldavia, Luxembourg, Cyprus, Montenegro, Ukraine, Malta.

${ }^{3}$ Belarus, Bosnia, Croatia, France and Spain. 
${ }^{4}$ Austria, Belgium, Denmark, Germany, Greece, Hungary, Italy, Lithuania, Norway, Poland, Portugal, Romania, Serbia, Slovakia, Slovenia, Sweden, Switzerland, Turkey.

${ }^{5}$ Finland, Ireland, Malta, the Netherlands, UK. ${ }^{6}$ Bulgaria, Czech Republic, Estonia, Latvia, Russia.

\section{Additional file}

Additional file 1: Appendix 1 Glossary, according to UEMS, 2003. Table S1. Data extraction form elaborated for adult psychiatry training. Table S2. Data extraction form elaborated for child and adolescent psychiatry training. (DOC $100 \mathrm{~kb}$ )

Additional file 2: Table S3. General and adult psychiatry training in Europe - Available data detailed for each country (1). (XLS $39 \mathrm{~kb}$ )

Additional file 3: Table S4. General and adult psychiatry training in Europe - Available data detailed for each country (2). (XLS $40 \mathrm{~kb}$ )

Additional file 4: Table S5. Child and adolescent psychiatry training in Europe - Available data detailed for each country (1). (XLS $41 \mathrm{~kb}$ )

Additional file 5: Table S6. Child and adolescent psychiatry training in Europe - Available data detailed for each country (2). (XLS 39 kb)

\section{Abbreviations}

AMHS: Adult Mental Health Service; AP: Adult Psychiatry; CAMHS: Child and Adolescent Mental Health Service; CAP: Child and Adolescent Psychiatry; CBT: Cognitive Behavioural Therapy; CME: Continuing Medical Education; EU: European Union; GAP: General and Adult Psychiatry; MHC: Mental Health Care; PRISMA: Preferred Reporting Items for Systematic Reviews and MetaAnalyses; UEMS: European Union of Medical Specialists

\section{Acknowledgements}

Current core members of the MILESTONE Consortium:

Swaran Singh, Helena Tuomainen, Jason Madan, Jane Warwick, Cathy Street, Dieter Wolke, Moli Paul, Priya Tah, Rebecca Appleton, Alastair Canaway, James Griffin (University of Warwick, UK), Giovanni de Girolamo, Giulia Signorini (Saint John of God Clinical Research Center, Italy), Santosh Paramala, Ilyas SagarOuriaghli, Natalie Heaney, Federico Fiori (Kings College London, UK), Diane Purper-Ouakil, Frédérick Russet, Virginie Maurice, Véronique Humbertclaude (Hôpital Saint Eloi, France), Athanasios Maras, Larissa van Bodegom, Mathilde Overbeek, Esther Kooymans (Yulius Academie, the Netherlands), Ulrike Schulze, Melanie Saam, Ulrike Breuninger (Universität, Germany), Sabine Tremmery, Gaëlle Hendrickx (KU Leuven, Belgium), Fiona McNicholas, Aleksandra Gronostaj (University College Dublin, Ireland), Tomislav Franić, Nikolina Davidović (University Hospital Split, Croatia), Frank Verhulst, Gwen Dieleman, Suzanne Gerritsen (Erasmus MC, The Netherlands), Kate Lievesley (HealthTracker, UK), Amanda Tuffrey, Anna Wilson, Charlotte Gatherer, Leanne Walker (Young project advisors). We also wish to address special thanks to Leny ALVERNHE for designing the map in Fig. 2.

\section{Funding}

The MILESTONE project received funding from the European Union's Seventh Framework Programme for research, technological development, and demonstration under grant agreement no 602442. The European Commission (FP7 programme) had no any role in our manuscript, no involvement in the writing of the manuscript or in the decision to submit the manuscript for publication. This Health Policy reflects only the authors' views and the EU is not liable for any use that might be made of the information contained therein.

\section{Availability of data and materials}

All data generated or analysed during this study are included in this published article and its supplementary information files.

\section{Authors' contributions}

FR and VH were in charge of the study desing, conducted the data search and analysis, and wrote the first draft of the manuscript. DP and ST were in charge of Work Package lead, study design and writing. SS, GD, KDC, GH, VK,
FN, AM, SP, MP, US, GS, CS, PT, HT provided substantial contribution to the final manuscript. All authors read and approved the final manuscript.

Ethics approval and consent to participate

Not applicable.

Consent for publication

Not applicable.

\section{Competing interests}

The authors declare that they have no competing interests.

\section{Publisher's Note}

Springer Nature remains neutral with regard to jurisdictional claims in published maps and institutional affiliations.

\section{Author details}

${ }^{1} \mathrm{CHU}$ Montpellier-Saint Eloi, Médecine Psychologique de l'Enfant et de I'Adolescent, 80, Av Fliche, 34295 Montpellier Cedex 5, France. ²Department of Child and Adolescent Psychiatry and Psychology, Erasmus University Medical Center, Rotterdam, Netherlands. ${ }^{3}$ University of Osijek, Osijek, Croatia. ${ }^{4}$ Department of Neurosciences, Child \& Adolescent Psychiatry, University of Leuven, Leuven, Belgium. ${ }^{5}$ Department of Child and Adolescent Psychiatry, School of Medicine and Medical Science and Geary Institute, University College Dublin, Dublin, Ireland. ${ }^{6}$ Yulius Academy, Rotterdam, Netherlands. ${ }^{7}$ Department of Child and Adolescent Psychiatry, Erasmus Medical Center-Sophia Children's Hospital, Rotterdam, Netherlands. ${ }^{8}$ Department of Child and Adolescent Psychiatry, Institute of Psychiatry, Psychology and Neuroscience, King's College London, London, UK. ${ }^{9}$ Centre for Interventional Paediatric Psychopharmacology and Rare Diseases (CIPPRD), National and Specialist Child and Adolescent Mental Health Services, Maudsley Hospital, London, UK. ${ }^{10}$ HealthTracker Ltd, Gillingham, UK. ${ }^{11}$ Mental Health and Wellbeing, Warwick Medical School, University of Warwick, Coventry, UK.

${ }^{12}$ Stratford Child and Adolescent Health Service, Coventry and Warwickshire Partnership Trust, Stratford on Avon, UK. ${ }^{13}$ Department of Child and Adolescent Psychiatry/Psychotherapy, University of Ulm, Ulm, Germany. ${ }^{14}$ Psychiatric Epidemiology and Evaluation Unit, Saint John of God Clinical Research Centre, Brescia, Italy. ${ }^{15}$ Department of Child \& Adolescent Psychiatry, University Hospitals Leuven, Leuven, Belgium.

Received: 14 November 2018 Accepted: 24 April 2019

Published online: 13 June 2019

\section{References}

1. Singh SP, Paul M, Ford T, Kramer T, Weaver T, McLaren S, et al. Process, outcome and experience of transition from child to adult mental health care: a multiperspective study. Br J Psychiatry. 2010;197:305-12.

2. Brodie I, Goldman R, Clapton J (2011, Revised 2014). Mental health service transitions for young people. Research briefing 37. Social Care Institute for Excellence www.scie.org.uk/publications/briefings.

3. Paul M, Street $C$, Wheeler N, Singh SP. Transition to adult services for young people with mental health needs: a systematic review. Clin Child Psychol Psychiatry. 2015;20(3):436-57.

4. Agarwal SD, Barnett ML, Souza J, Landon BE. Adoption of Medicare's transitional care management and chronic care management codes in primary care. JAMA. 2018;320(24):2596-7.

5. Burke L, Kirkham J, Arnott J, Gray V, Peak M, Beresford MW. The transition of adolescents with juvenile idiopathic arthritis or epilepsy from paediatric health-care services to adult health-care services: a scoping review of the literature and a synthesis of the evidence. J Child Health Care. 2018;22(3):332-58.

6. Wright C, Steinway C, Jan S. The genesis of systems of care for transition to adulthood services: emerging models in primary and subspecialty care. Curr Opin Pediatr. 2018:30(2):303-10.

7. Royal College of Paediatrics and Child Health. 2003. Bridging the gaps: healthcare for adolescents. www.rcpsych.ac.uk.

8. Health and Social Care Advisory Service (HASCAS). HASCAS tools for transition - CAMHS to adult transition. A literature review for informed practice. London: Health and Social Care Advisory Service; 2006.

9. McDonagh JE, Viner RM. Lost in transition? Between paediatric and adult services. BMJ. 2006;332:435-6. 
10. Singh SP, Tuomainen $H$, de Girolamo G, Maras A, Santosh P, et al. Protocol for a cohort study of adolescent mental health service users with a nested cluster-randomised controlled trial to assess the clinical and cost effectiveness of managed transition in improving transitions from child to adult mental health services (The MILESTONE study). BMJ Open. 2017. https://doi.org/10.1136/bmjopen-2017-016055.

11. Singh SP. Transition of care from child to adult mental health services: the great divide. Curr Opin Psychiatry. 2009;22(4):386-90.

12. Signorini G, Singh SP, Marsanic VB, Dieleman G, Dodig-Ćurković K, Franic T, et al. The interface between child/adolescent and adult mental health services: results from a European 28-country survey. Eur Child Adolesc Psychiatry. 2018:1-11. https://doi.org/10.1007/s00787-018-1112-5.

13. Union Européenne des Médecins Spécialistes (UEMS), Section for Psychiatry - European Board of Psychiatry. Charter on training of medical specialist in the EU - Requirements for the speciality of psychiatry. 2017. From https:// www.uems.eu/_data/assets/pdf_file/0019/43561/ETR-Psychiatry-201703.pdf.

14. Liberati A, Altman DG, Tetzlaff J, Mulrow C, Gøtzsche PC, loannidis JPA, et al. The PRISMA statement for reporting systematic reviews and meta-analyses of studies that evaluate health care interventions: explanation and elaboration. Plos Med. 2009;6(7):e1000100-e.

15. Joanna Briggs Institute (2016) Critical appraisal tools. http://joannabriggs. org/research/critical-appraisal-tools.html.

16. Hawker S, Payne S, Kerr C, Hardey M, Powell J. Appraising the evidence: reviewing disparate data systematically. Qual Health Res. 2002;12(9): 1284-99.

17. Margariti M, Kontaxakis VP, Madianos M, Feretopoulos G, Kollias K, et al. Psychiatric education: a survey of Greek trainee psychiatrists. Med Educ. 2002;36(7):622-5.

18. Karabekiroglu K, Doğangün B, Hergüner $S$, von Salis T, Rothenberger A. Child and adolescent psychiatry training in Europe: differences and challenges in harmonization. Eur Child Adolesc Psychiatry. 2006;15(8):467-75.

19. Lotz-Rambaldi W, Schafer I, ten Doesschate R, Hohagen F. Specialist training in psychiatry in Europe--results of the UEMS-survey. Eur Psychiatry. 2008; 23(3):157-68. https://doi.org/10.1016/j.eurpsy.2007.12.001.

20. Julyan TE. Educational supervision and the impact of workplace-based assessments: a survey of psychiatry trainees and their supervisors. BMC Med Educ. 2009;9:51. https://doi.org/10.1186/1472-6920-9-51.

21. Kuzman MR, Jovanović N, Vidović D, Margetić BA, Mayer N, Plestina S, et al. Problems in the current psychiatry residency training program in Croatia: residents' perspective. Coll Antropol. 2009;33(1):217-23.

22. Nawka A, Kuzman MR, Giacco D, Malik A. Mental health reforms in Europe: challenges of postgraduate psychiatric training in Europe: a trainee perspective. Psychiatr Serv. 2010;61(9):862-4. https://doi.org/10.1176/appi.ps.61.9.862.

23. Oakley C, Malik A. Psychiatric training in Europe. Psychiatrist. 2010;34(10): 447-50. https://doi.org/10.1192/pb.bp.109.026062.

24. Fiorillo A, Luciano M, Giacco D, Del Vecchio V, Baldass N, Oakley C, et al. Training and practice of psychotherapy in Europe: results of a survey. World Psychiatry. 2011;10(3):238.

25. Gomez-Beneyto M, Montilla-García JF, De Castro-Manglano P, Gay-Pamos E, González-Torres MA, Vallejo-Ruiloba J, et al. (2011) La opinión de los residentes de psiquiatría sobre la formación que reciben. (Spanish). The opinion of psychiatric residents on the training they receive. Actas Esp Psiquiatr. 2011;39(3):174-9.

26. Van Effenterre A. Formation et information des internes en psychiatrie: quelle place pour la recherche? (French) education and training of young psychiatrists: is there time for research? Encephale. 2011;37(3):159-61. https://doi.org/10.1016/j.encep.2010.08.008.

27. Kuzman MR, Giacco D, Simmons M, Wuyts $P$, Bausch-Becker N, Favre G, Nawka A. Are there differences between training curricula on paper and in practice? Views of European trainees. World Psychiatry. 2012;11(2):135. https://doi.org/10.1016/j.wpsyc.2012.05.013.

28. Kuzman MR, Giacco D, Simmons M, Wuyts P, Bausch-Becker N, Favre G, Nawka A. Psychiatry training in Europe: views from the trenches. Med Teach. 2012;34(10):e708-17. https://doi.org/10.3109/0142159X.2012.687481.

29. Simmons M, Barrett $E$, Wilkinson P, Pacherova L. Trainee experiences of child and adolescent psychiatry (CAP) training in Europe: 2010-2011 survey of the European Federation of Psychiatric Trainees (EFPT) CAP working group. Eur Child Adolesc Psychiatry. 2012;21(8):433-42. https://doi.org/10. 1007/s00787-012-0275-8.

30. Pinto da Costa M, Guerra C, Malta R, Moura M, Carvalho S, Mendonça D. Psychiatry training towards a global future: trainees' perspective in Portugal. Acta Med Port. 2013;26(4):357-60.
31. Van Effenterre A, Azoulay M, Champion F, Briffault X. Initial training in psychotherapy for psychiatrists in France: results of a national survey. Encephale. 2013;39(3):155-64. https://doi.org/10.1016/j.encep.2012.05.003.

32. Van Effenterre A, Hanon C, Llorca PM. (Enquête auprès des PU-PH Sur la formation en psychiatrie en France.) survey among academic teachers about psychiatric training in France. Encephale. 2014;40(3):208-15. https:// doi.org/10.1016/j.encep.2013.05.001.

33. Fabrega M, Ilzarbe D. Becoming a child and adolescent psychiatrist in Spain: trainees' perspectives. Eur Child Adolesc Psychiatry. 2017;26(6):743-5.

34. Hansen LK, Thomsen AF. Psychiatric training in two different EU countries: Denmark and the UK. Psychiatrist. 2000;24(8):309-11. https://doi.org/10. 1192/pb.24.8.309.

35. Füredi J, Mohr P, Swingler D, Bitter I, Gheorghe MD, Sartorius N, et al. Psychiatry in selected countries of central and Eastern Europe: an overview of the current situation. Acta Psychiatr Scand. 2006;114(4):223-31.

36. Zisook S, Balon R, Björkstén KS, Everall I, Dunn L, Yoo T, et al. Psychiatry residency training around the world. Acad Psychiatry. 2007;31(4):309-25.

37. Naber D, Hohagen F. Training in psychiatry and psychotherapy in Germany. Encephale. 2008;34(2):107-9. https://doi.org/10.1016/j.encep.2007.09.001.

38. Garret-Gloanec, N. (2010). La FMC est-elle DPC au profit de I'EPP ? (French) L'Information Psychiatrique, 86(5), 379-383. doi: https://doi.org/ 10.1684/ipe.2010.0642.

39. Javed MA, Ramji MA, Jackson R. The changing face of psychiatry training in the UK. Indian J Psychiatry. 2010;52(1):60-5. https://doi.org/ 10.4103/0019-5545.58897.

40. Bobes J, Garcia-Portilla MP, Bobes-Bascaran MT, Parellada M, Bascaran MT, Arango C, et al. The state of psychiatry in Spain. Int Rev Psychiatry. 2012; 24(4):347-55. https://doi.org/10.3109/09540261.2012.691090.

41. Palha A, Marques-Teixeira J. The emergence of psychiatry in Portugal: from its roots to now. Int Rev Psychiatry. 2012;24(4):334-40.

42. Van Schijndel MA, Gerrits WL, Niesink P, van der Gaag RJ. The state of psychiatry in the Netherlands: strength by quality, influence by capabilities. Int Rev Psychiatry. 2012;24(4):321-7. https://doi.org/10.3109/09540261.2012.694360.

43. Crommen S. Child and adolescent psychiatry in Belgium and the Flemish Association for Child and Adolescent Psychiatry. Eur Child Adolesc Psychiatry. 2013;22(4):263-4. https://doi.org/10.1007/s00787-013-0402-1.

44. Skokauskas N (2013) Postgraduate Training in Psychiatry in Ireland. https:// www.jspn.or.jp/journal/symposium/pdf/jspn108/ss782-786.pdf.

45. Van Effenterre A. Formation en pédopsychiatrie en France: historique, actualités et réflexions. Inf Psychiatr. 2013;89(7):599-604.

46. Fegert J, Schepker R, Banaschewski T, Flechtner H. Child and adolescent psychiatry in Germany. Eur Child Adolesc Psychiatry. 2014;23(7):621-2.

47. Mayer S, van der Gaag RJ, Dom G, Wassermann D, Gaebel W, Falkai P, Schüle C, European Psychiatric Association. European psychiatric association (EPA) guidance on post-graduate psychiatric training in Europe. Eur Psychiatry. 2014;29(2):101-6. https://doi.org/10.1016/j.eurpsy.2014.01.002.

48. Christodoulou N, Kasiakogia K. Psychiatry training in the United Kingdom -part 2: the training process. Psykiatriki. 2015;26(1):55-60.

49. Karwautz A, Purtscher-Penz AK, Hochgatterer P, Kienbacher C, Board of the Austrian Society of Child and Adolescent Psychiatry. Child and adolescent psychiatry in Austria. Eur Child Adolesc Psychiatry. 2015;24(3):359-60. https://doi.org/10.1007/s00787-014-0657-1.

50. Drobnic M. The state of child and adolescent psychiatry in Slovenia: a brief report. Eur Child Adoles Psychiatry. 2016;25(5):561-3.

51. Buftea L, Cretu C, Mihai A. 10 years re-evaluation of number of psychiatric residents involved in training in psychotherapy in Romania. Eur Psychiatry. 2010;25:1064. https://doi.org/10.1016/S0924-9338(10)71054-3.

52. Barrett EP, Nawka A, Malik A, Giacco D, Rojnic-Kuzman M, Simmons M, Favre G. Child and adolescent psychiatry training in Europe: Views of trainee representatives for 2009-2010 to the European Federation of Psychiatric Trainees. Eur Psychiatry. 2011;26:266. https://doi.org/10.1016/S09249338(11)71976-9.

53. Giacco D. ECP09-05 - psychiatric training in europe: the opinions of early career psychiatrists. Eur Psychiatry. 2011;26:1809. https://doi.org/10.1016/ S0924-9338(11)73513-1.

54. Kokras N, Samiotakis G, Gerasi E, Oikonomou D, Ntoumanis A, Psarras R. A survey on psychiatric training in Greece from trainees' perspective. Eur Psychiatry. 2011;26:1730. https://doi.org/10.1016/S09249338(11)73434-4.

55. Atti AR, Forlani M, Morri M, Fiorillo A, Volpe U, De Rosa C, Ferrari S. Quality of training program for early-career psychiatrists in Italy: focus on forensic 
psychiatry and psychotherapy. Eur Psychiatry. 2012;27:1. https://doi.org/10. 1016/S0924-9338(12)74587-X.

56. Lee A, Noonan A. Psychotherapy training in Ireland: a survey of college tutors. Ir J Psychol Med. 2012;29(1):41-5

57. Bulletin Officiel No39 du 28 octobre 2004. From https://www.affep.fr/ formation/formation.php.

58. Royal College of Psychiatrists (2010, Revised 2016). A competency based curriculum for specialist training in psychiatry. Specialists in General Psychiatry. https://www.rcpsych.ac.uk/pdf/General_Psychiatry_Curriculum_ August_2016.pdf.

59. College of Psychiatry of Ireland (2016). Curriculum for basic and higher specialist training in psychiatry. http://www.irishpsychiatry.ie/wp-content/ uploads/2016/12/Curriculum-for-Basic-Higher-Specialist-Training-inPsychiatry-July-2016.pdf.

60. Royal College of Psychiatrists (2013, updated 2016). A Competency Based Curriculum for Specialist Core Training in Psychiatry. Core training in Psychiatry CT1-CT3. https://www.rcpsych.ac.uk/pdf/Core_Psychiatry_ Curriculum_August_2016.pdf.

61. Royal College of Psychiatrists (2013). A competency based curriculum for specialist training in psychiatry. Specialists in Child and Adolescent Psychiatry. https://www.gmc-uk.org/-/media/documents/Amended_Child and_Adolescent_Curriculum_January_2018.pdf_72924518.pdf.

62. Hill P, Rothenberger A. Can we - and should we have a europsychiatry for children and adolescents? The work of the UEMS section and board for child and adolescent psychiatry/psychotherapy. Eur Child Adolesc Psychiatry. 2005;14(8):466-70.

63. Brittlebank A, Hermans M, Bhugra D, Pinto Da Costa M, Rojnic-Kuzman M, Van der Gaag RJ, et al. Training in psychiatry throughout Europe. Eur Arch Psychiatry Clin Neurosci. 2016;266:155-64. https://doi.org/10.1007/s00406-016-0679-4.

64. Weerasekera P, Feinstein RE. The future of psychiatric education: an international perspective. Acad Psychiatry. 2013;37(4):229-32.

65. Muijen M. Training psychiatrists in Europe: fit for purpose? Commentary on... Psychiatric training in Europe. Psychiatric Bull. 2010;34:450-1. https://doi.org/ 10.1192/pb.bp. 110.030189

66. Union Européenne des Médecins Spécialistes, Section of Psychiatry (2014) Annual Report. http://uemspsychiatry.org/h/board/.

67. Fegert et al. (2016) Transition from adolescence to adulthood: the challenges to establish "transition psychiatry". https://www.escap.eu/care/ transition-to-adulthood-and-effective-mental-health-care/transition-keyissues-paper.

68. Carver J, Cappelli M, Davidson S, Caldwell W, Belair MA, Vloet M. Taking the next step forward: building a responsive mental health and addictions system for emerging adults. Ottawa: Mental Health Commission of Canada; 2015.

69. McGorry P, Bates T, Birchwood M. Designing youth mental health services for the 21st century: examples from Australia, Ireland and the UK. Br J Psychiatry. 2013;202(s54):s30-5.

70. Pottick KJ, et al. US patterns of mental health service utilization for transition-age youth and young adults. J Behav Health Serv Res. 2008; 35(4):373-89.

71. Nguyen T, Embrett MG, Barr NG, Mulvale GM, Vania DK, Randall GE, DiRezze B. Preventing youth from falling through the cracks between child/ adolescent and adult mental health services: a systematic review of models of care. Community Ment Health J. 2017;53(4):375-82.

72. Davis M, Sondheimer DL. State child mental health efforts to support youth in transition to adulthood. J Behav Health Serv Res. 2005;32(1):27-42.

73. Clark HB, Davis M. Transition to adulthood: a resource for assisting young people with emotional or behavioral difficulties; 2000.

74. Singh SP, Tuomainen $\mathrm{H}$, de Girolamo G, et al. Protocol for a cohort study of adolescent mental health service users with a nested cluster-randomised controlled trial to assess the clinical and cost effectiveness of managed transition in improving transitions from child to adult mental health services (The MILESTONE study). BMJ Open. 2017. https://doi.org/10.1136/bmjopen2017-016055

75. Union Européenne des Médecins Spécialistes, Section of Psychiatry (2016) Annual Report. http://uemspsychiatry.org/h/board/.

76. Lamb C, Hall D, Kelvin R, Van Beinum M. Working at the CAMHS/adult Interface: good practice guidance for the provision of psychiatrists services to adolescents/young adults. London: Royal College of Psychiatrists; 2008.
77. Society for Adolescent Medicine. Transition to adult health care for adolescents and young adults with chronic conditions. Position paper for the Society of Adolescent Medicine. J Adolesc Health. 2003;33:309-11.

78. Hall CL, Newell K, Taylor J, Sayal K, Swift KD, Hollis C. 'Mind the gap' mapping services for young people with ADHD transitioning from child to adult mental health services. BMC Psychiatry. 2013;13:186. https://doi.org/10. 1186/1471-244X-13-186

79. Bartsocas C. From adolescence to adulthood: the transition from child to adult care. Health Deliv. 2007:52:3.

80. Blum RW, Garell D, Hodgman CH, Jorissen TW, Okinow NA, Orr DP, Slap GB. Transition from child-centered to adult health-care systems for adolescents with chronic conditions: a position paper of the Society for Adolescent Medicine. J Adolesc Health. 1993;14(7):570-6.

81. Jivanjee P, Kruzich JM, Gordon LJ. The age of uncertainty: parent perspectives on the transitions of young people with mental health difficulties to adulthood. J Child Fam Stud. 2009;18(4):435-46.

82. Lamb C, Murphy M. The divide between child and adult mental health services: points for debate. BJP. 2013;202:s41-4. https://doi.org/10.1192/bjp. bp.112.119206.

83. Bruce H, Evans N. The transition into adult care. Psychiatry. 2008;7(9):399-402.

84. Moscoso A, Jovanovic N, Rojnic M. Transition from adolescent to adult mental health services in Europe from the provider's perspective. Lancet Psychiatry. 2015;2(9):779-80.

\section{Ready to submit your research? Choose BMC and benefit from:}

- fast, convenient online submission

- thorough peer review by experienced researchers in your field

- rapid publication on acceptance

- support for research data, including large and complex data types

- gold Open Access which fosters wider collaboration and increased citations

- maximum visibility for your research: over $100 \mathrm{M}$ website views per year

At BMC, research is always in progress.

Learn more biomedcentral.com/submissions 